\title{
Joining Techniques For Ferritic ODS Alloys
}

\author{
V. G. Krishnardula \\ D. E. Clark \\ T. C. Totemeier \\ June 2005
}

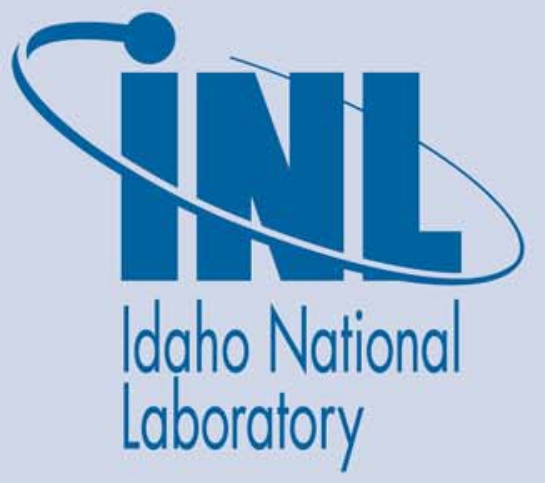

The INL is a U.S. Department of Energy National Laboratory operated by Battelle Energy Alliance 
INL/EXT-05-00385

\title{
Joining Techniques for Ferritic ODS Alloys
}

\author{
V.G. Krishnardula*, D.E. Clark, and T.C. Totemeier \\ * Materials Research and Education Center, Auburn University, Auburn, AL
}

June 2005

Idaho National Laboratory

Idaho Falls, Idaho 83415

Prepared for the

U.S. Department of Energy

Office of Nuclear Energy

Under DOE Idaho Operations Office

Contract DE-AC07-05ID14517 
Joining Techniques for Ferritic ODS Alloys

INL/EXT-05-00385

June 2005

Approved by

Bevan D. Cleaver

June 1, 2005

Kevan D. Weaver

Date 


\section{SUMMARY}

This report presents results of research on advanced joining techniques for ferritic oxide-dispersion strengthened alloys MA956 and PM2000. The joining techniques studied were resistance pressure welding (also known as pressure forge welding), transient liquid phase bonding, and diffusion bonding. All techniques were shown to produce sound joints in fine-grained, unrecrystallized alloys. Post-bond heat treatment to produce a coarse-grained, recrystallized microstructure resulted in grain growth across the bondline for transient liquid phase and diffusion bonds, giving microstructures essentially identical to that of the parent alloy in the recrystallized condition. The effects of bond orientation, boron interlayer thickness, and bonding parameters are discussed for transient liquid phase and diffusion bonding. The report concludes with a brief discussion of ODS joining techniques and their applicability to GEN IV reactor systems. 



\section{CONTENTS}

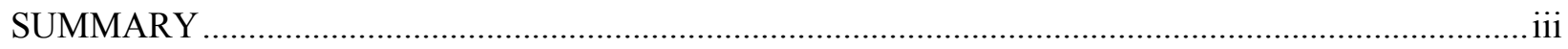

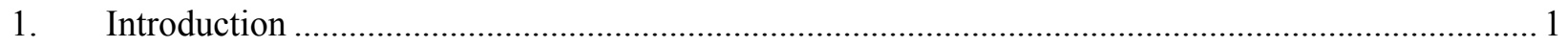

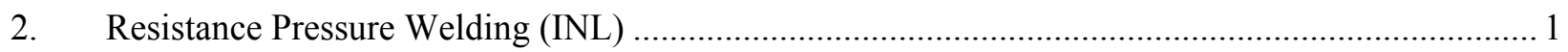

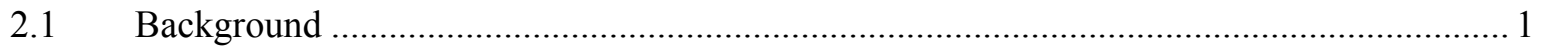

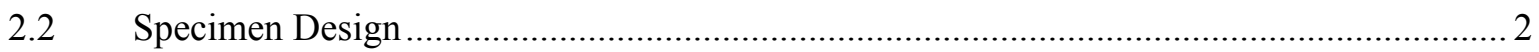

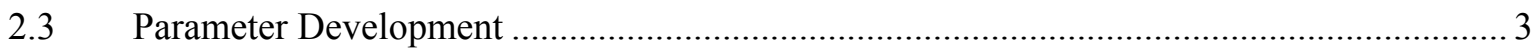

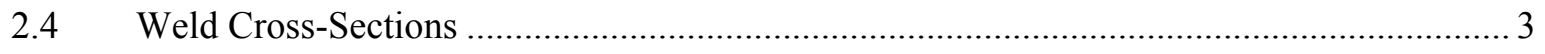

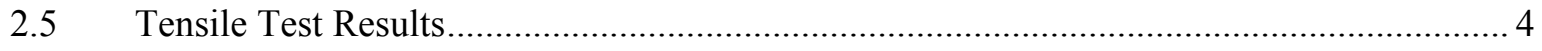

2.6 Torsional Resistance Pressure Welding .................................................................... 6

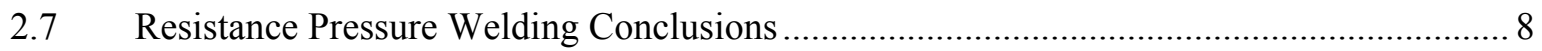

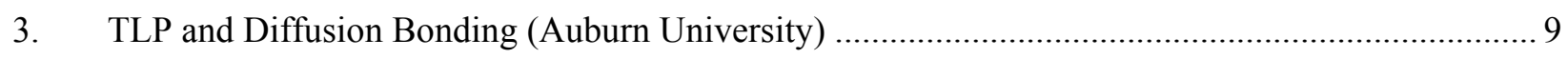

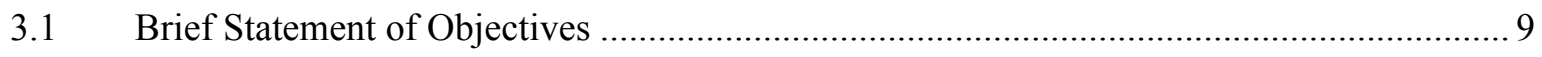

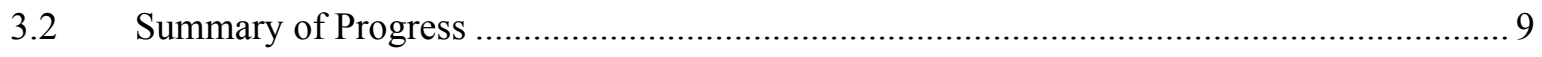

3.2.1 Substrate and Interlayer Materials........................................................... 9

3.2.2 Bonding Trials and Post-Bond Heat-Treatment .......................................... 10

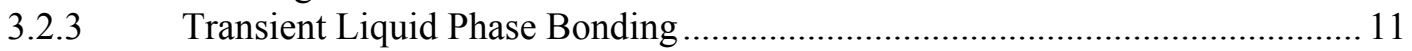

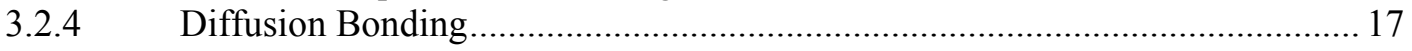

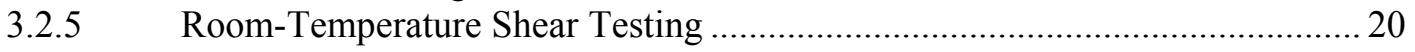

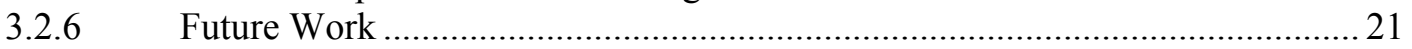

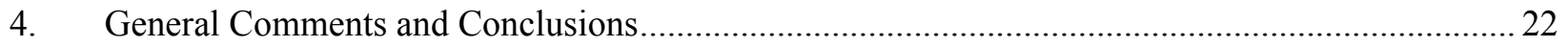

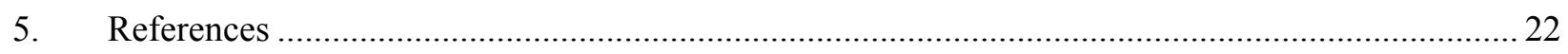




\section{Joining Techniques for Ferritic ODS Alloys}

\section{Introduction}

This report summarizes the results of research into advanced joining techniques for ferritic oxidedispersion strengthened (ODS) alloys funded by the Generation IV (GEN IV) gas fast reactor (GFR) program from March 2003 to May 2005. The primary application of ODS alloys in the GFR is as fuel cladding and endcaps, where both resistance to high-temperature deformation and radiation stability are required. ODS alloys appear to meet these needs, but joining techniques are required which preserve their microstructure and intrinsic strength. Fusion welding, commonly used for metals, is not ideal for ODS alloys because melting disrupts both the fine, uniform dispersion of nano-sized oxide particles and the coarse grain structure of recrystallized ODS alloys. Other joining techniques studied to date include friction welding [1,2], laser welding [3], brazing [4], resistance pressure welding (RPW) [5], diffusion bonding [6], and transient liquid-phase (TLP) bonding [7-9]. Of these techniques, only the last three offer the possibility of forming sound joints with minimal disruption to both the oxide dispersion and the parent grain structure. With bonding processes performed in a fine-grained, unrecrystallized condition it may be possible to achieve coarse grain growth across the bondline during recrystallization treatment after bonding, giving joint properties equivalent to the base metal.

Research into the resistance pressure welding technique, also termed resistance forge welding was carried out at the INL by D.E. Clark. Research into TLP and diffusion bonding techniques was performed at Auburn University by V.G. Krishnardula under the supervision of Prof. W.F. Gale. The TLP and diffusion bonding research is on-going. Results of the two research programs are summarized in sections 2 and 3 of this report, followed by overall discussion of the applicability of ODS joining techniques for the GFR and other GEN IV applications.

\section{Resistance Pressure Welding (INL)}

\subsection{Background}

Solid state joining processes require the disruption of surface oxides and other contamination, and also typically require high temperatures to promote interdiffusion or grain growth across the boundary to produce a monolithic structure without melting, which would destroy the unique advantages of mechanically alloyed materials. Diffusion welding and transient liquid phase bonding meet this requirement with little plastic deformation by achieving close contact at high temperatures for relatively long periods (time scale: many minutes or hours), and by paying close attention to the relevant thermally activated phenomena. The flash welding method developed at ANL-W and further refined in Japan [5] meets this requirement because, although it involves melting and vaporization at the interface (required to disrupt surface contamination), the rapid expulsion of vaporized or melted material as the parts are quickly assembled (time scale: milliseconds) leaves a joint composed essentially of unmelted material in which the dispersed oxides are undisturbed.

The approach taken in the present work, resistance pressure welding (or resistance forge welding) meets this requirement also by using high temperatures (achieved by resistive heating of the parts to be joined), but in addition causing intense plastic deformation at the interface (time scale: seconds to tens of seconds), which both disrupts surface contamination and provides a driving force for dynamic recrystallization across the interface. 


\subsection{Specimen Design}

Specimen design has evolved over the course of the project, beginning with a simple tapered design in inexpensive conventional stainless steel materials. Design changes were made iteratively based on successive results. The end cap design shown in Figure 1 is the latest design; it provides a $2 \mathrm{~mm}$ land slightly larger in diameter than the ID of the simulated tubing (machined from PM2000 material), and a tapered section to expand the tube on insertion.

The restraining ring, also made from PM2000, serves to provide the backing force for plastic deformation at the interface. The 3-4 $\mathrm{mm}$ wide notch in the ring provides a location for the control thermocouple to attach at the weld zone, and also facilitates the removal of the ring for further specimen testing. The ID of the ring was machined to match the computed OD of the tubing after expansion by the inserted end cap. This proved to provide insufficient restraint, so later welds were made with 0.008 in. shim stock between ring and tube.

Optimized welds made with this configuration are repeatable both in appearance and in measured parameters, and failed in tension in the tubing, away from the weld area.
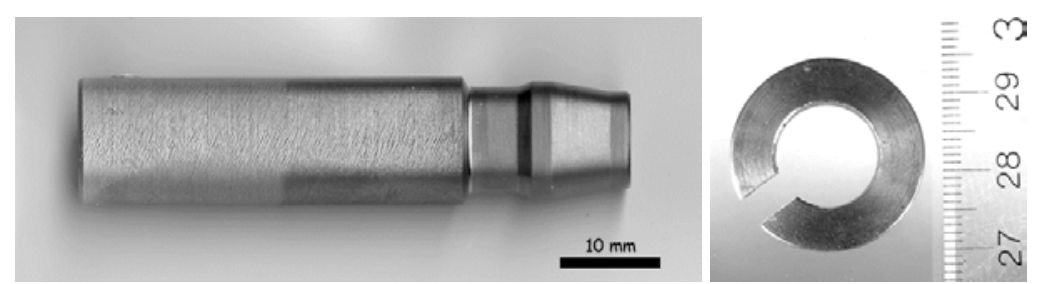

Figure 1. Insert specimen and restraining ring for resistance pressure welding, PM2000 material. 


\subsection{Parameter Development}

The thermomechanical cycle finally developed for this phase of the joining effort involves the steps shown in Figure 2.

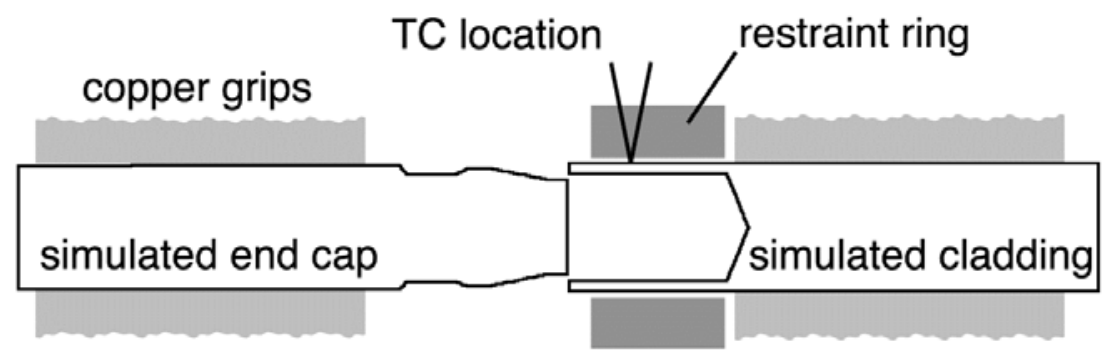

starting position

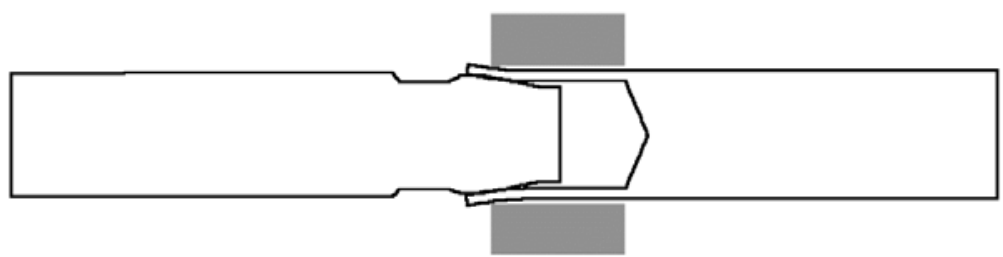

insert cold to $9 \mathrm{~mm}$, heat to $1000^{\circ} \mathrm{C}$

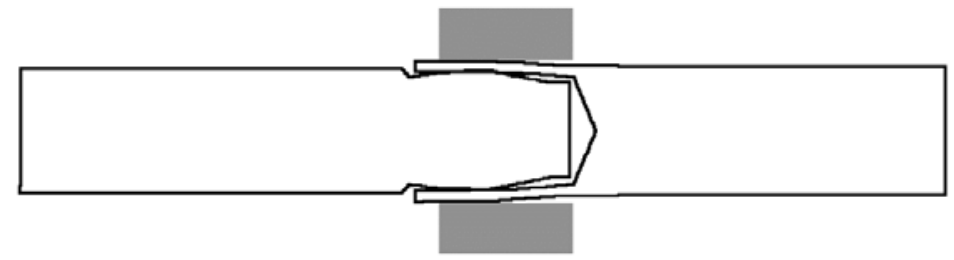

insert at temperature to $16 \mathrm{~mm}$, cool under compressive load

Figure 2. Welding technique for PM2000 material developed in current work.

\subsection{Weld Cross-Sections}

The effects of specimen design and welding parameters were initially characterized by metallographic cross sections to measure the bonded area and examine the plastic flow phenomena. Figure 3 shows such a cross section optically, and Figure 4 shows the upper weld on this specimen on the SEM. The short cycle times at 900 to $1000^{\circ} \mathrm{C}$ were not expected to cause the growth of the very large grains typical of these alloys (and desirable for high-temperature service); the existing fine grain structure was not resolved with the etching techniques used. 


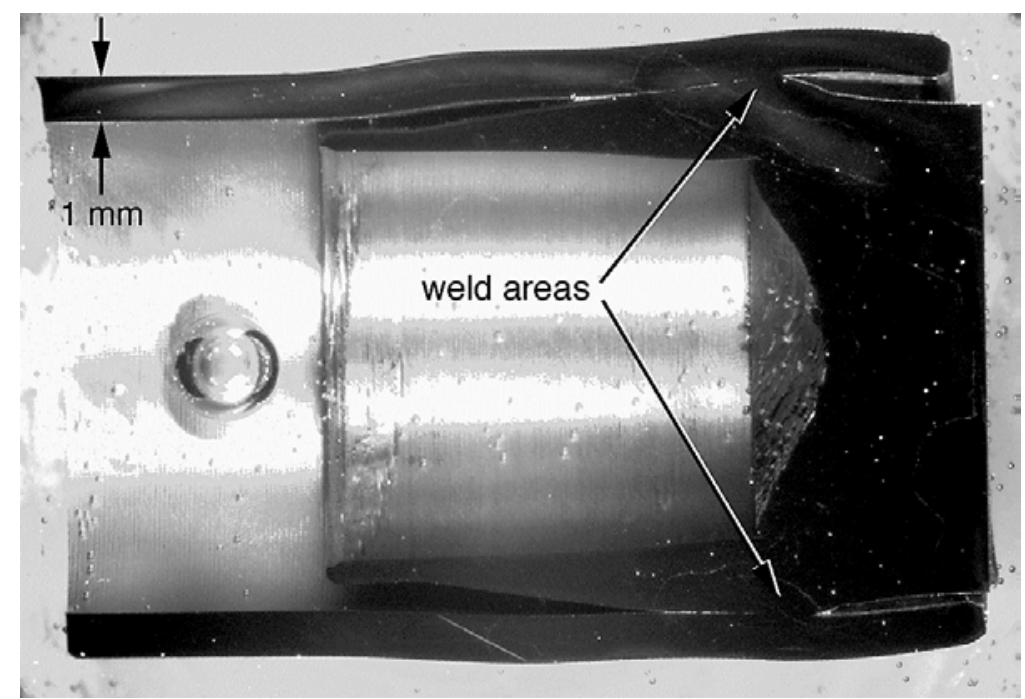

Figure 3. Cross section of typical weld (sectioned and polished material is dark).

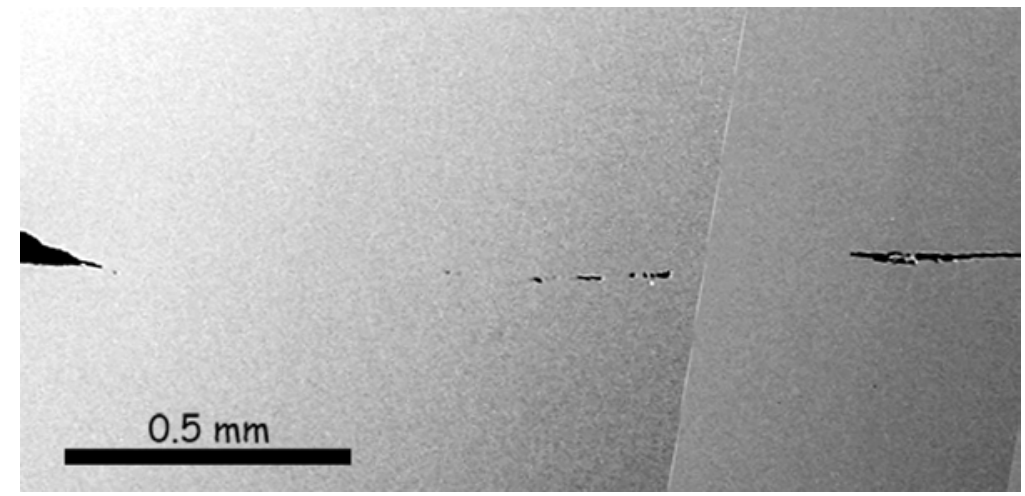

Figure 4. SEM view of unetched weld in PM2000 fine-grained material. Examination at higher magnification indicated full bonding in apparent bonded areas.

\subsection{Tensile Test Results}

In the later stages of parameter development, once consistent welds were achieved as judged by the metallographic cross sections, tensile tests were performed. After welding, the restraining ring was slid off, pins were inserted in holes at the distal ends of the joined parts (for positive gripping by the Gleeble's unthreaded clamping copper blocks), and they were returned to the Gleeble for mechanical testing.

The basic service criterion for this joint was taken to be an axial load due to internal pressurization of the fuel cladding by gaseous fission products, at transient temperatures up to $900^{\circ} \mathrm{C}$. The internal area of the tube is $0.139 \mathrm{in}^{2}$ and the wall thickness is $1 \mathrm{~mm}\left(0.0394 \mathrm{in}\right.$.), yielding an annular area of $0.0570 \mathrm{in}^{2}$. The loads and stresses in Table 1 would apply: 
Table 1. Load and pressure relationships.

\begin{tabular}{lcc}
\hline $\begin{array}{l}\text { Internal Pressure } \\
(\mathrm{psi})\end{array}$ & $\begin{array}{c}\text { Axial Load } \\
(\mathrm{lbs})\end{array}$ & $\begin{array}{c}\text { Axial Stress in Wall } \\
(\mathrm{ksi})\end{array}$ \\
\hline 1000 & 139 & 2446 \\
2000 & 279 & 4893 \\
5000 & 697 & 12,232 \\
10,000 & 1394 & 24,464 \\
\hline
\end{tabular}

Near the end of the process development cycle thus far, a nominal insertion distance of $15 \mathrm{~mm}$ was used. These welds failed in tension at the weld interface at loads corresponding to fairly high internal pressures, but in an effort to increase weld strength, insertion distance was increased to $16 \mathrm{~mm}$. These welds failed outside the weld joints, at loads indicated in Table 2, and the broken specimens are shown in Figures 5 and 6.

Table 2. Tensile test results for welds.

\begin{tabular}{lcccc}
\hline $\begin{array}{l}\text { Insertion } \\
\text { Distance } \\
(\mathrm{mm})\end{array}$ & $\begin{array}{c}\text { Test } \\
\text { Temperature } \\
\left({ }^{\circ} \mathrm{C}\right)\end{array}$ & $\begin{array}{c}\text { Axial } \\
\text { Load } \\
(\mathrm{lbs})\end{array}$ & $\begin{array}{c}\text { Cladding Wall } \\
\text { Stress } \\
(\mathrm{ksi})\end{array}$ & $\begin{array}{c}\text { Corresponding } \\
\text { Internal Pressure } \\
(\mathrm{psi})\end{array}$ \\
\hline 15 & 20 & 2236 & 39.2 & 16,000 \\
15 & 900 & 1190 & 20.9 & 8540 \\
16 & 20 & 7942 & 139.4 & 57,000 \\
16 & 900 & 1193 & 20.9 & 8560 \\
\hline
\end{tabular}

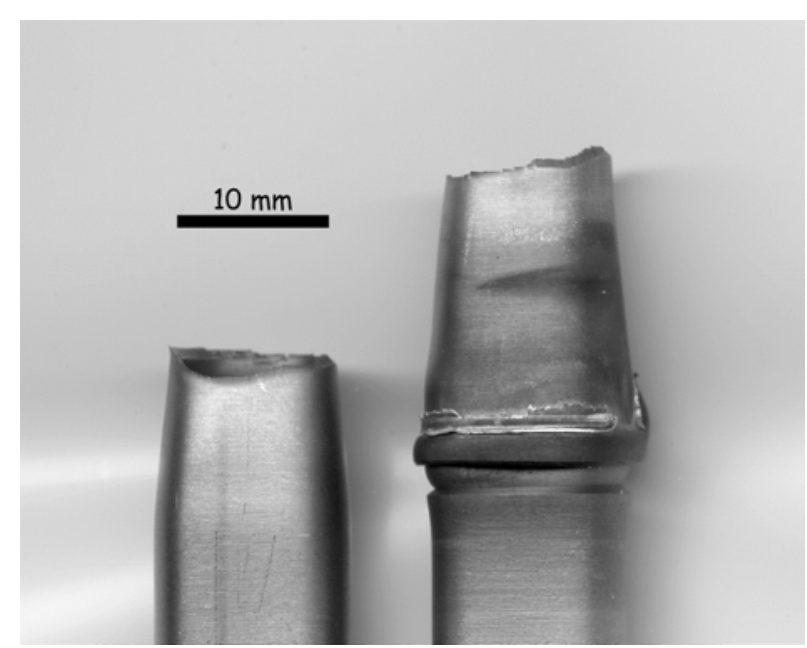

Figure 5. Pressure forge weld in PM2000 material, tensile tested at room temperature, failure away from weld at load of 7,942 pounds. 


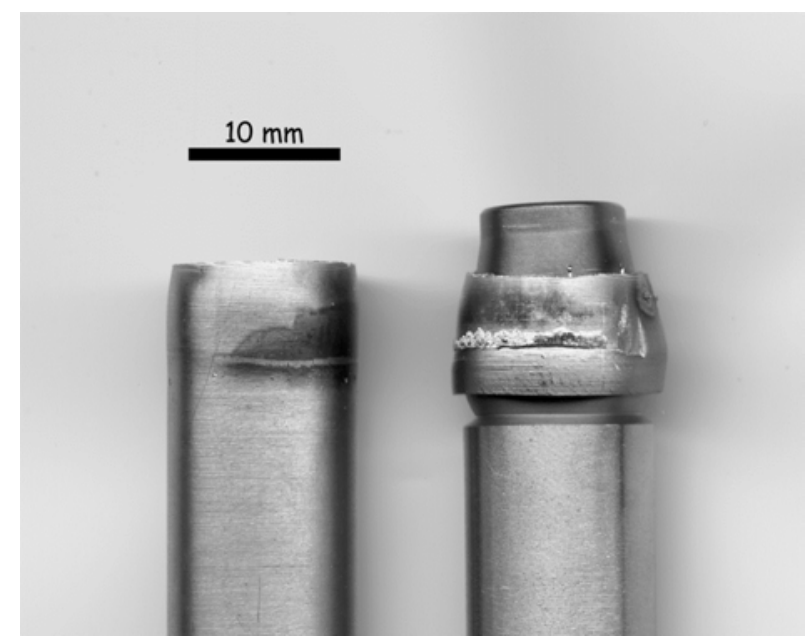

Figure 6. Pressure forge weld in PM2000 material, tensile tested at $900{ }^{\circ} \mathrm{C}$, failure away from weld at load of 1,193 pounds.

\subsection{Torsional Resistance Pressure Welding}

As indicated in previous reports, an axial motion was used for convenience because that was the loading mode of the existing Gleeble configuration. One limitation of the axial welds discussed above is the limited travel (a few $\mathrm{mm}$ ), which limits the fresh material that can be brought into contact during the welding process. It also necessitates some diametrical change in the cladding to assure intimate contact, though this could probably be minimized with proper design and fixturing.

In January 2005, a torsional Gleeble load unit was purchased, which permits hydraulically controlled motion in both axial and torsional directions, and this opened an opportunity for another kind of resistance pressure weld. Fixtures were made which adapted this unit, which is designed for multipleturn, high-strain and high strain rate torsion testing, as shown in Figure 7. This type of welding addresses the shortcomings of axial welding: with many rotations available, many linear $\mathrm{mm}$ of travel would be possible with each weld, leading to more complete surface oxide removal at lower axial loads and hence with less massive machinery; suitably restrained, the cladding wall itself can bear the axial loads.

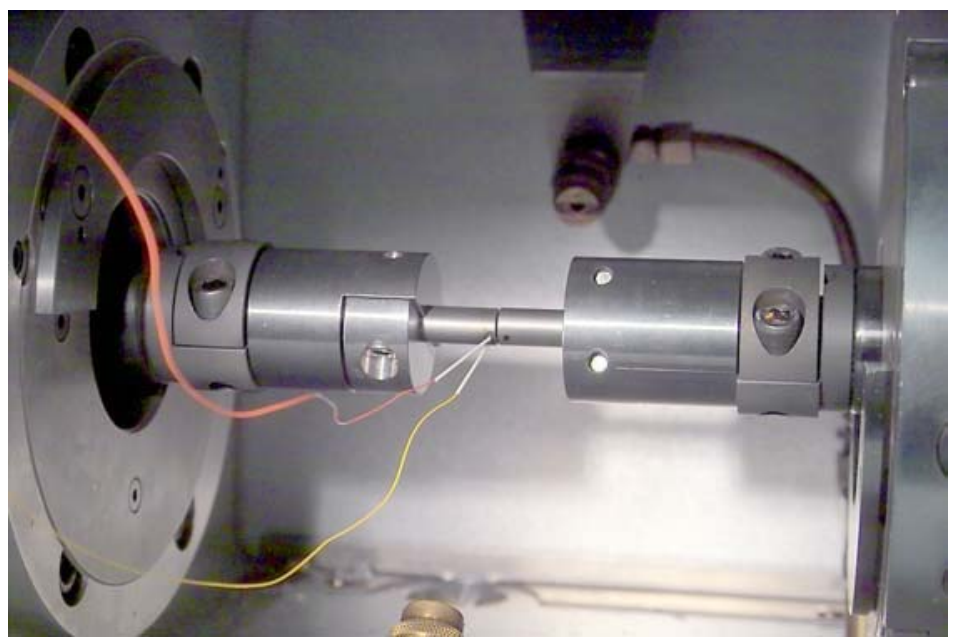

Figure 7. Simulated fuel cladding (left) and end cap (right) prior to welding. 
There were some unanticipated alignment problems with the fixtures: as can be seen in Figure 7, the parts do not quite align. There was also excessive runout in the rotating side (right side in the figure), sometimes amounting to approximately the wall thickness of the parts $(10 \mathrm{~mm}$ diameter, $1.0 \mathrm{~mm}$ wall, approximating a nominal cladding dimension). The fixtures holding the parts were not designed to compensate for this, and in a complete rotation it was found that the combination of axial force and runout led to gross deformation of the weld zone. This was remedied in later welds by reducing the axial force and using a torsion program that moved $60^{\circ}$ several times rather than a full turn in one direction. An example of the better, later specimens is shown in Figure 8, where misalignment is nonetheless apparent. A cross section of a weld similar to that shown in Figure 8 is shown in Figure 9, and at higher magnification in Figure 10.

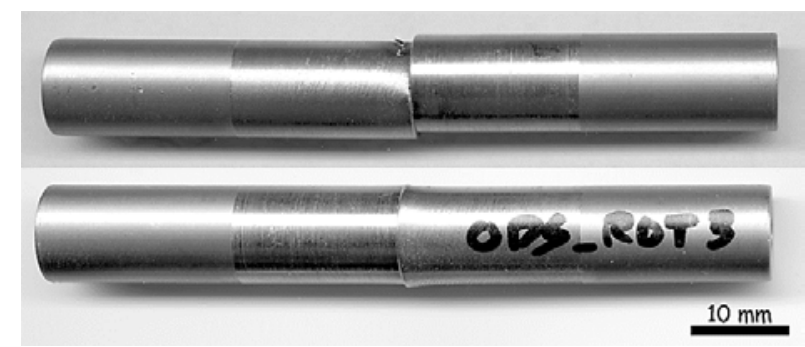

Figure 8. Typical torsional mode weld, illustrating results of fixture misalignment. Axial load $300 \mathrm{~N}$ $(\sim 67 \mathrm{lbf})$, torsional motion $+30^{\circ},-60^{\circ},+30^{\circ}$ over $2 \mathrm{~s}$, temperature $850^{\circ} \mathrm{C}$.

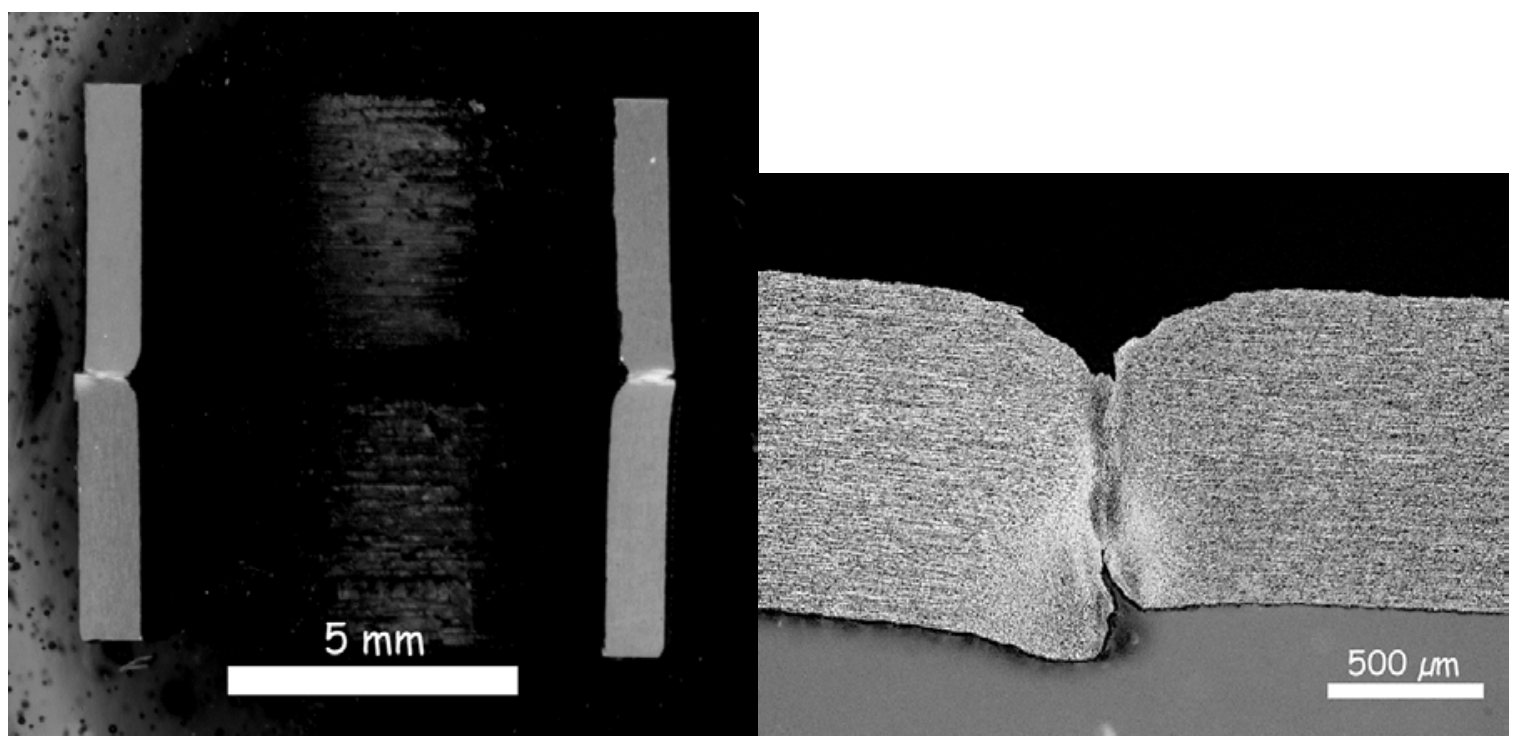

Figure 9. Cross section of torsional mode weld, axial load $100 \mathrm{~N}(\sim 22 \mathrm{lbf})$, torsional motion $+30^{\circ},-60^{\circ}$, $+60^{\circ},-60^{\circ},+30^{\circ}$ over $4 \mathrm{~s}$, temperature $850^{\circ} \mathrm{C}$. 


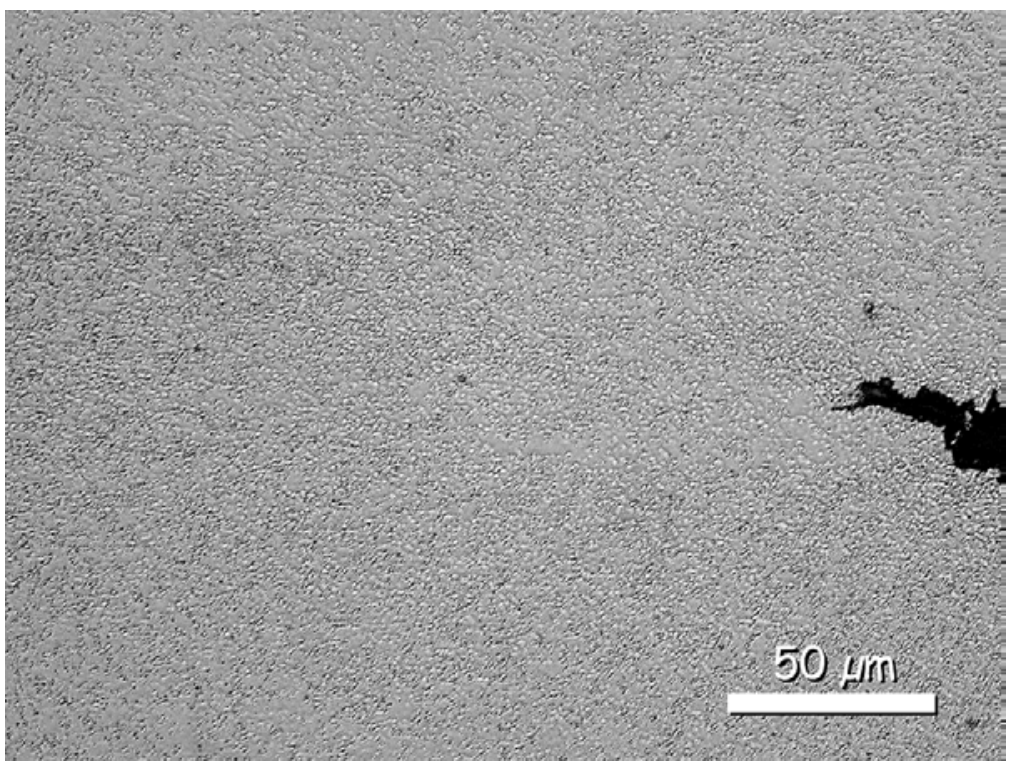

Figure 10. Weld area at higher magnification, showing complete bonding and fine grain size.

\subsection{Resistance Pressure Welding Conclusions}

Based on the present work, the torsional joint seems the most promising, although the axial joint could probably be made to work. A fully optimized joint was not attempted in these trials, for several reasons, primarily, in the case of the torsional joint, the misalignment and runout of the rotary fixtures, and an unintentional chamfer on the simulated tube ends.

The metallurgical processes seem sound, however, but should be easily achievable in a system custom-designed for the production welding of fuel rod end caps. Such a system, which requires relatively low loads and heating capacities, would be much smaller than the multi-purpose Gleeble, and in fact intrinsically relatively inexpensive. Design features of such a system would include:

- Precision fixtures, tooling, and workpiece specifications yielding close axial and joint face alignment;

- Well controlled actuators, probably electrical rather than hydraulic based on the low loads required;

- A power supply for resistance heating of the joining surface, probably transformer/SCR based;

- PC-based control and data acquisition.

Since the critical welding time for these designs is several seconds long, it should be possible to develop correlations between the various resulting forces and displacements to assure weld quality in these difficult-to-inspect welds. Further work needs to be done in the metallurgical characterization of the joints, including the capacity to grow the desirable large grains across the interface if ODS materials are chosen for reactor applications. The basic process, however, should be adaptable to the joining of any metals. 


\section{TLP and Diffusion Bonding (Auburn University)}

\subsection{Brief Statement of Objectives}

This project aims to develop a high-performance joining technology for ferritic ODS alloys. The key objective of the research is to develop a technology that can be used to bond ODS fuel cans to end caps without compromising the creep resistance of the ODS alloy.

TLP bonding was employed in this work due to its potential to obtain metallurgically sound bonds with properties comparable to those of parent metal $[10,11]$. Interlayers for the TLP bonding of iron or nickel-base alloys commonly contain significant amounts of boron as a melting-point depressant [12]. Boron diffuses rapidly as an interstitial and hence allows short process times. However, boron is too large for the available interstitial sites and hence imposes a significant strain on the solvent's lattice. This strain can induce undesired recrystallization [13]. Commercially available interlayers are in the form of foils and are initially dispersoid-free. The key issues associated with using foils are excessive parent metal dissolution and boron induced recrystallization [14]. Excessive dissolution of the substrates causes agglomeration of the yttria particles resulting in dispersoid-free regions at the bondline. The depletion of strengthening oxides at the bondline can lead to poor mechanical properties. Thin coatings have the potential to reduce these problems. Although TLP bonding was the initially-proposed joining technique in this project, solid-state diffusion bonding was also investigated. Diffusion bonding requires no additional material or melting of the base metal, and hence possesses the potential to obtain complete microstructural continuity across the bondline. However, diffusion bonding commonly requires the application of relatively high stresses across the bond-line $[15,16]$, which may increase processing complexity.

The objectives of the proposed research are to:

- Design and implement a bonding process that provides reasonable dispersoid continuity across the bondline of ferritic ODS alloy joints.

- Produce a recrystallized microstructure that is at least approximately continuous across the bondline, with grain sizes and aspect ratios reasonably similar to those in unbonded material.

\subsection{Summary of Progress}

\subsubsection{Substrate and Interlayer Materials}

Various ODS materials were received from INL (Table 3). These were MA956 in both the fine grain (unrecrystallized) and coarse grain (recrystallized) conditions, and PM 2000 in the fine grain (unrecrystallized) condition. The intent was ultimately to concentrate effort on the PM 2000 alloy, due to availability. However, the MA956 was received first and initial work was conducted on MA956.

Boron was selected as the melting-point depressant for the TLP bonding work due to the high diffusion coefficient of boron in ferritic materials (no boron diffusion data specific to ODS alloys has been found in the literature). Pure boron coatings were used as interlayers, which form a eutectic by reaction with the ODS alloy substrates. $250 \mathrm{~nm}, 500 \mathrm{~nm}$ and $1 \mu \mathrm{m}$ thick boron films were used as interlayers. It is important to note that the actual width of the liquid seam produced in these bonds is far wider than the width of the as-deposited interlayer. The boron interlayers were deposited using electron beam physical vapor deposition (EBPVD) in Auburn's microelectronic fabrication facility. 
Table 3. Materials and chemical compositions.

\begin{tabular}{llllllllll}
\hline Alloy & As-Received Condition & \multicolumn{7}{c}{ Composition (wt \%) } \\
\cline { 3 - 8 } & & Fe & B & Si & Cr & Al & Ti & $\mathrm{Y}_{2} \mathrm{O}_{3}$ & C \\
\cline { 3 - 8 } MA956 & $\begin{array}{l}\text { Fine grained (unrecrystallized) condition } \\
-11 \text { mm square bar }\end{array}$ & bal & -- & -- & 20 & 4.5 & 0.5 & 0.5 & -- \\
& $\begin{array}{l}\text { Coarse grain (recrystallized) condition } \\
-20 \text { mm diameter bar }\end{array}$ & & & & & & & & \\
PM2000 & $\begin{array}{l}\text { Fine grain (unrecrystallized) condition }- \\
\text { 25 and 50 mm diameter bar }\end{array}$ & bal & -- & -- & 20 & 5.5 & 0.5 & 0.5 & $<0.04$ \\
Boron & $\begin{array}{l}\text { Formed by electron-beam physical vapor } \\
\text { deposition }\end{array}$ & -- & 100 & -- & -- & -- & -- & -- & -- \\
Fe-Si-B & Foil & bal & 16 & 5 & -- & -- & -- & -- & -- \\
\hline
\end{tabular}

\subsubsection{Bonding Trials and Post-Bond Heat-Treatment}

A Gleeble 1500 thermo-mechanical processing system was employed for bonding trials to allow both rapid heating and the ability to apply pressure. Limited joining work was also conducted using a radiantly heated (refractory metal heating element) vacuum furnace. In the latter case, only a fixturing load was employed and a relatively low heating rate was used $\left(2-4^{\circ} \mathrm{C} \mathrm{s}^{-1}\right.$ for the furnace, as compared with $8-10{ }^{\circ} \mathrm{C} \mathrm{s}^{-1}$ for the Gleeble). Rapid heating rates are necessary to prevent excessive boron diffusion during heating to the bonding temperature, which would impede (or maybe even prevent) liquid formation at the bonding temperature. The heating rate used in the Gleeble would be attainable in a commercial induction brazing operation, but is far higher than the heating rates achievable with a commercial vacuum brazing furnace. Furthermore, even the lower $2 \mathrm{C} \mathrm{s}^{-1}$ heating rate used for furnace brazing in the present project is an order of magnitude higher than standard furnace brazing practice.

An electric discharge machine (EDM) was used to cut $11 \mathrm{~mm} \times 10 \mathrm{~mm} \times 2 \mathrm{~mm}$ thick substrates in longitudinal and transverse orientations (along and normal to the direction of extrusion, respectively, as shown in Figure 11). The substrates were then surface ground to a roughness of around $1 \mu \mathrm{m}$, both top and bottom, for flatness and parallel surfaces. The substrates were cleaned with acetone and stored in acetone to avoid formation of oxide layers. Bonding was conducted at $1250{ }^{\circ} \mathrm{C}$ in a vacuum of less than $1 \times 10^{-3} \mathrm{~Pa}$ using different bond orientation as shown in Figure 12. Compressive stresses in the range of 1-5 MPa were employed to extrude the excess liquid formed at the bondline. Post bond heat treatment (PBHT) was conducted in the radiantly heated furnace at a vacuum less than $1 \times 10^{-3} \mathrm{~Pa}$ at $1300^{\circ} \mathrm{C}$ and $1385^{\circ} \mathrm{C}$ for MA956 and PM2000 materials, respectively, to induce recrystallization. A solution of $2 \mathrm{~g}$ copper chloride, $40 \mathrm{ml}$ hydrochloric acid and 40-70 ml methanol for 2-10 seconds was used for etching. Microstructural evaluation was performed using optical microscopy and scanning electron microscopy (JEOL 840 SEM, operating at $20 \mathrm{kV}$ ). Energy dispersive spectroscopy (EDS) was also conducted using the JEOL 840 to investigate the material composition across the bondline. 


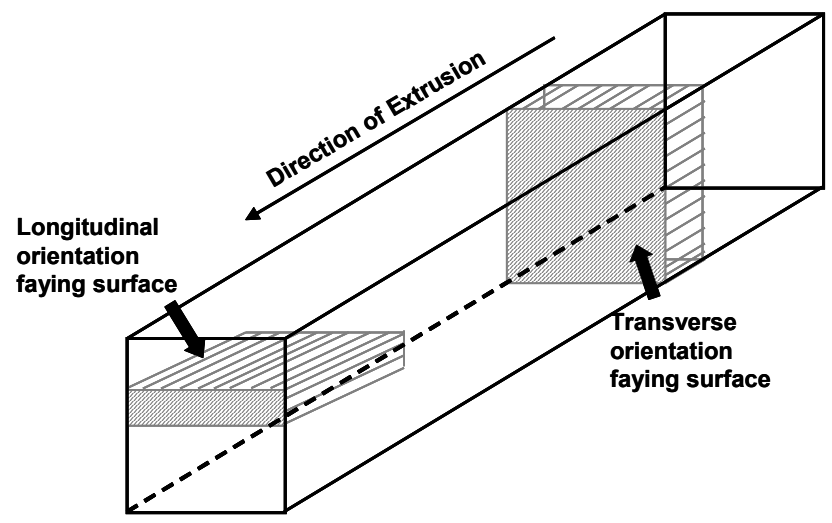

Figure 11. Substrates in longitudinal and transverse orientations.
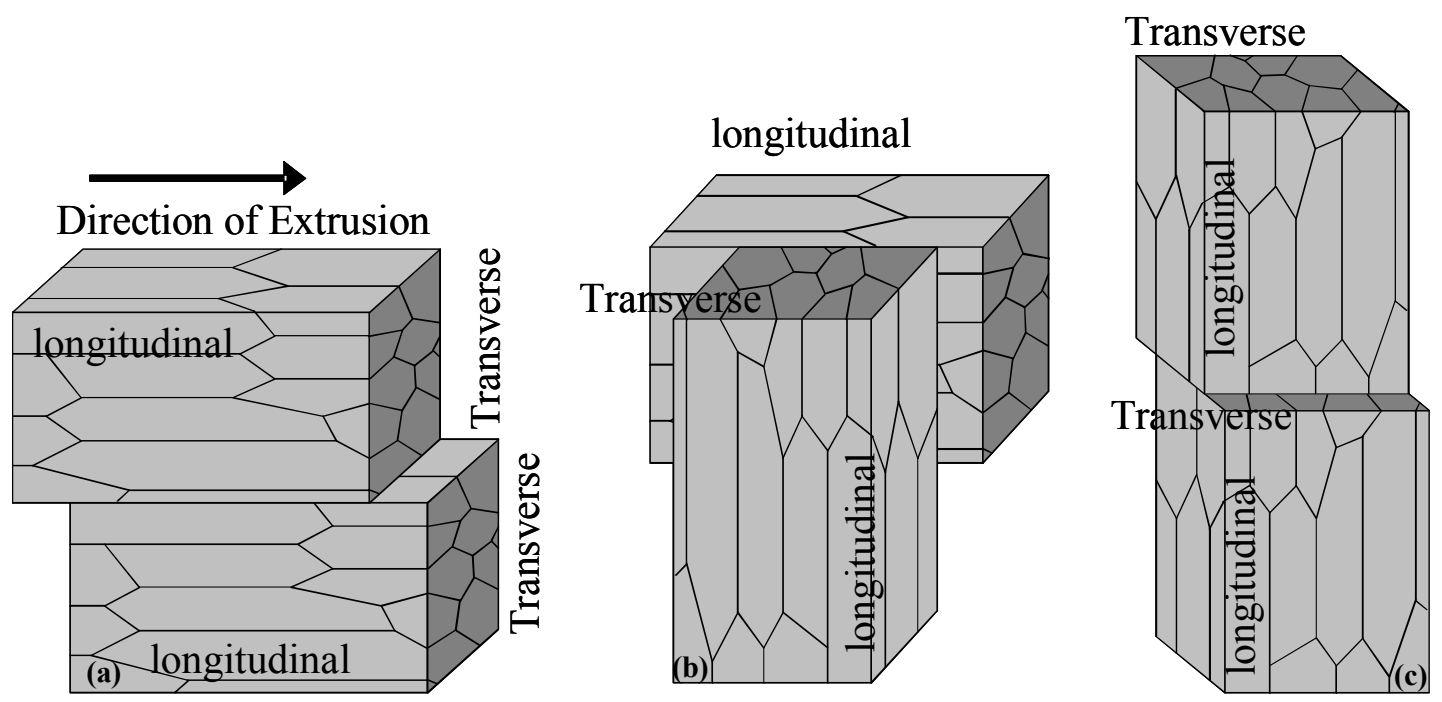

Figure 12. Different bond orientations with respect to direction of extrusion: (a) longitudinallongitudinal (L-L), (b) longitudinal-transverse (L-T), and (c) transverse-transverse (T-T).

\subsubsection{Transient Liquid Phase Bonding}

Initial bonds conducted using the MA956 fine grain substrate and $1 \mu \mathrm{m}$ boron interlayer at $1250^{\circ} \mathrm{C}$ (to be above the eutectic melting temperature of Fe-B alloy system) for bonding times from 20 seconds to 1 hour formed borides at the bondline to different extents. It was observed that the amount of boride formation decreased with bonding time. The centerline eutectic was removed by the 1 hour bonding treatment, but boride formation in the adjacent substrates was still seen. However, the duration of the bonding treatment does not appear to be nearly as significant as that of the $\mathrm{PBHT}$ at $1300^{\circ} \mathrm{C}$, especially as no borides were apparent after PBHT, regardless of the bonding time (Figure 13).

PBHT was conducted from 1 hour up to 8 hours at $1300^{\circ} \mathrm{C}$ to induce recrystallization in the substrates, as opposed to the standard $1 \mathrm{~h}, 1300^{\circ} \mathrm{C}$ recrystallization anneal for MA956. However, the 
PBHT only led to partial recrystallization in the substrates. To further investigate recrystallization in the substrate material, both as-received unrecrystallized and as-received recrystallized MA956 unbonded bulk substrates were exposed to a thermal cycle similar to that of the bonded material. The difference in the recrystallization can be seen in Figure 14. In spite of the prolonged recrystallization heat treatment, the grain size in the initially fine grained material was much smaller than that of the initially coarse-grained material. However, some variation in the recrystallization in the fine grain material was also observed.
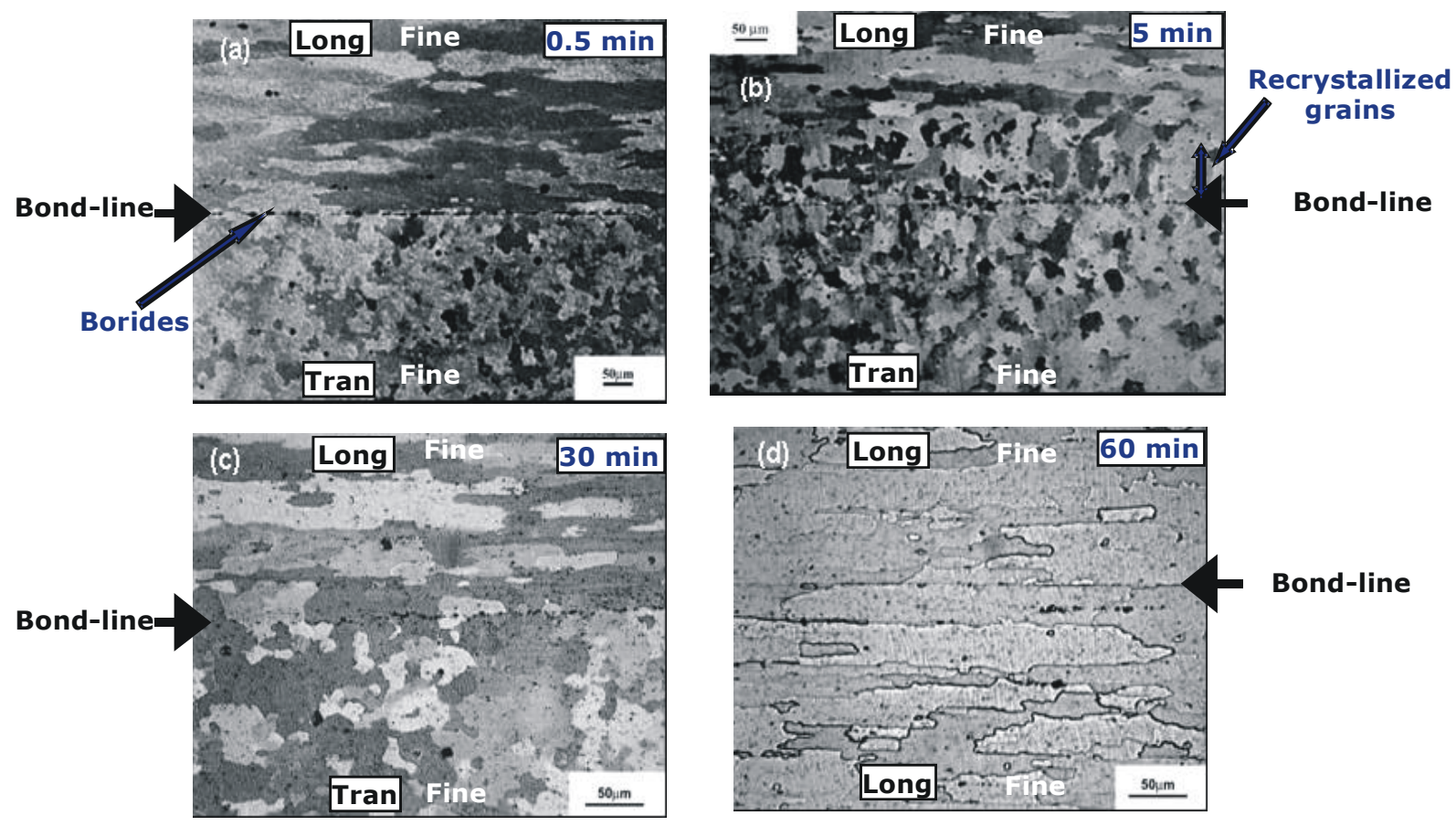

Figure 13. MA956 fine-grained substrates bonded using $1 \mu \mathrm{m}$ boron interlayer at $1250^{\circ} \mathrm{C}$ for: (a) 0.5 $\min (\mathrm{L}-\mathrm{T})$, (b) $5 \min (\mathrm{L}-\mathrm{T})$, (c) $30 \mathrm{~min}(\mathrm{~L}-\mathrm{T})$, and (d) $60 \mathrm{~min}(\mathrm{~L}-\mathrm{L})$ and PBHT $8 \mathrm{hr}, 1300^{\circ} \mathrm{C}$. Note (1) the decrease in the boride formation with increase in bonding time and (2) secondary recrystallized grain growth in different bond orientations. 

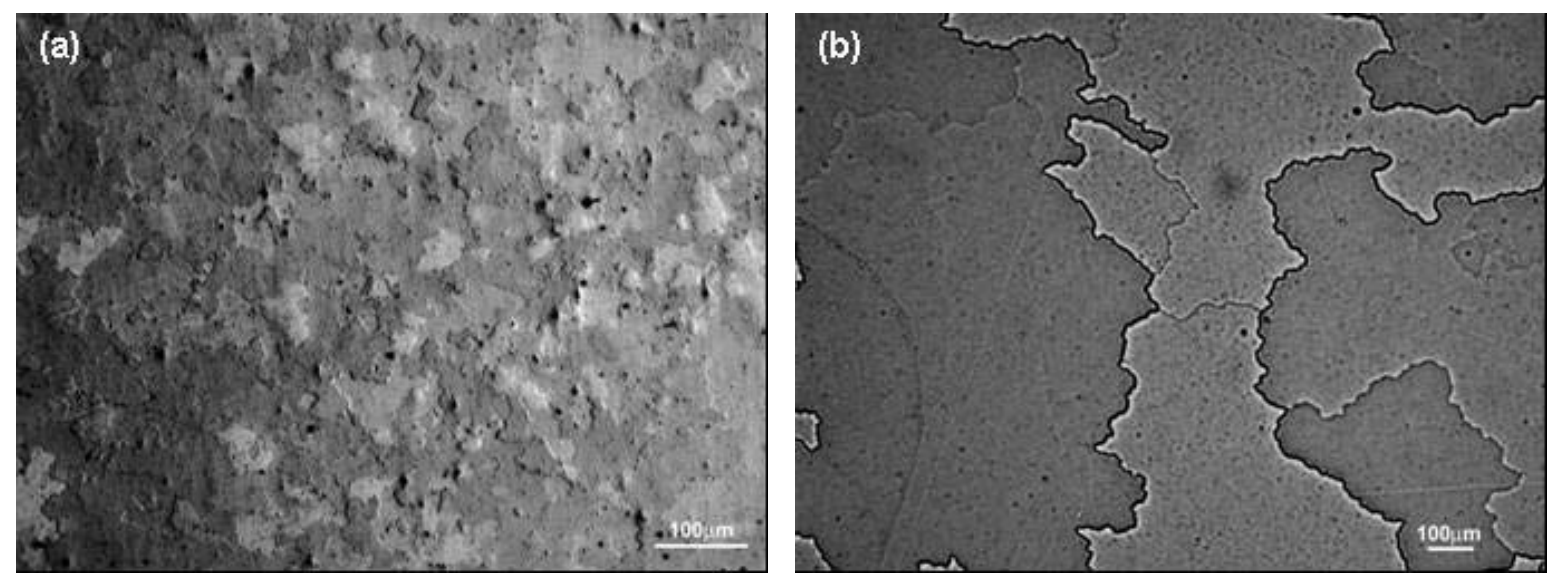

Figure 14. MA956 transverse orientation unbonded bulk material: (a) as-received, uncrecrystallized material exposed to $8 \mathrm{~h}, 1300^{\circ} \mathrm{C}$, smaller grains (b) as-received recrystallized material exposed to $1 \mathrm{~h}$, $1300^{\circ} \mathrm{C}$, larger grains.

ODS alloys obtain their high temperature properties as a result of the nano-sized yttria dispersoids. These oxide particles are aligned in the direction of extrusion or rolling. Mechanically alloyed ODS alloys retain large amounts of stored energy in the unrecrystallized state due to the extensive cold deformation during high-energy milling. Any disturbance to the yttria alignment due to substrate melting can result in the formation of equiaxed grains which leads to poor creep strength [4]. The number of yttria stringers cut by the bondline is governed by the direction of the substrate faying surface. Aligning the substrate faying surfaces in the working direction reduces the number of yttria stringers cut by the bondline. Joining was investigated with different bond orientations as shown in Figure 12. Example bonds can be seen in Figures 13 and 15-17. Formation of secondary recrystallized grains was observed in the different bond orientations investigated, but the extent of the formation of the equiaxed grains varied with each orientation as listed in Table 4. The best results to date were obtained with the longitudinal-longitudinal bond orientation. Energy dispersive spectroscopy (EDS) showed uniform composition across the bondline (see Figure 15).

The extent of uncontrolled recrystallization in the substrates was reduced with a decrease in the interlayer thickness. MA956 fine grain material bonded using a $0.5 \mu \mathrm{m}$ boron interlayer exhibited less uncontrolled recrystallization compared to bonds made using a $1 \mu \mathrm{m}$ boron interlayer. This can be attributed to less liquid formed at the bondline as a result of the reaction of the interlayer with the substrate faying surface. The amount of boride formation at the bondline decreased in bonds made using the $0.5 \mu \mathrm{m}$ boron interlayer, as shown in Figure 16, which is directly related to the amount of boron available at the bondline to be diffused into the substrate. For comparison, conventional bonding (brazing) was conducted using a Fe-16B-5Si foil. Surprisingly, a very well wetted bond was made, but the original foil was still observed at the bondline and recrystallized grain growth across the bondline did not occur.

Fine-grained material was the primary material used for bonding trials in order to achieve recrystallization in the material across the bondline during post bond heat treatment, and successful bonds were obtained with MA956. Bonds using coarse-grained (recrystallized) substrates were also prepared for comparison. Fine-grain - coarse-grain and coarse-grain - coarse-grain bonds were fabricated using a $1 \mu \mathrm{m}$ boron interlayer. Equiaxed, fine grains were formed at the bondline in both cases. The thickness of the layer of equiaxed grains varied from 30-50 $\mu \mathrm{m}$ and 10-15 $\mu \mathrm{m}$ for fine-grain - coarse-grain and coarsegrain - coarse-grain bonds, respectively. The best results to date were obtained with fine-grained substrates. 
Bonding trials then moved to PM2000 material with longitudinal-longitudinal bond orientations (since the best results on MA956 were obtained with the longitudinal-longitudinal bond orientation). Initial attempts using fine-grained PM2000 material were made using a $0.250 \mu \mathrm{m}$ boron interlayer. Post bond heat treatment of 2 hours at $1385^{\circ} \mathrm{C}$ resulted in continuous grain growth across the bondline as shown in Figure 17. No secondary equiaxed grains at the bondline were observed.

Joining PM2000 fine grain material in the longitudinal-longitudinal orientation with a $1 \mu \mathrm{m}$ boron interlayer resulted in a well wetted bond interface (Figure 18a). PBHT resulted in recrystallization of the substrate material, but significant porosity was observed both in the bulk and at the bondline (Figure 18b). A thick layer of fine grains was observed near the bond interface with a number of smaller pores (Figure 18c). To further investigate the quality of the as-received PM2000 material, a survey including microstructure analysis and compositional mapping was conducted. Pore formation during heat treatment (observed earlier by other researchers $[14,17,18]$, and variation in composition was observed in the recrystallized material. The presence of porosity, rather than etching or polishing pits, was confirmed by metallography on some of the same substrates at INL. Chen et al. [18] explained the pore formation as due to the release of the trapped gases that are used for shielding purposes in the mechanical alloying of the material. Some regions also showed unacceptable defects such as random formation of fine grains in the bulk and at the edges of the substrate (Figure 18d). The variation in porosity and unwanted fine grain formation during recrystallization heat treatment is obvious in Figures $18 \mathrm{~d}$ and $18 \mathrm{e}$. Fine grains formed at the substrate edges are somewhat similar to those observed near the bond region in Figure 18c. The release of the gases seems to form new surfaces at the bondline. These new surfaces, hence, might undergo similar fine grain formation as observed at the substrate edges. The recrystallization and porosity in the bonds could therefore be the result of defects in the bulk material. However, boron induced secondary recrystallization cannot be completely ruled out.

Table 4. Effect of bond-line orientation on the extent of uncontrolled recrystallization in the vicinity of the bond-line. Data shown are for MA 956. Based on the data acquired so far, occasional region to region differences within a given sample are significant and the bond orientation influences the extent of fine grain formation.

\begin{tabular}{ll}
\hline $\begin{array}{l}\text { Bond Geometry } \\
\text { (Compare with Figures 13,15-17) }\end{array}$ & $\begin{array}{l}\text { Extent of Uncontrolled Recrystallization Leading to Layer of Fine } \\
\text { Grained Regions at or Near Bond-Line }\end{array}$ \\
\hline $\begin{array}{l}\text { Longitudinal-Longitudinal } \\
\text { (L-L) }\end{array}$ & $\begin{array}{l}\text { Usually minor and does not extend significantly into substrates. } \\
\text { Zero (no secondary recrystallized grains) up to } 20 \mu \mathrm{m} \text { wide. }\end{array}$ \\
& $\begin{array}{l}\text { Some samples had isolated recrystallized regions up to } \sim 50 \mu \mathrm{m} \text { wide. } \\
\text { Extensive and continues up to } \sim 100 \mu \mathrm{m} \text { into longitudinal substrate. }\end{array}$ \\
Longitudinal-Transverse (L-T) & \begin{tabular}{l} 
Varies between 30 to $50 \mu \mathrm{m}$ wide. \\
\hline
\end{tabular} \\
\hline
\end{tabular}



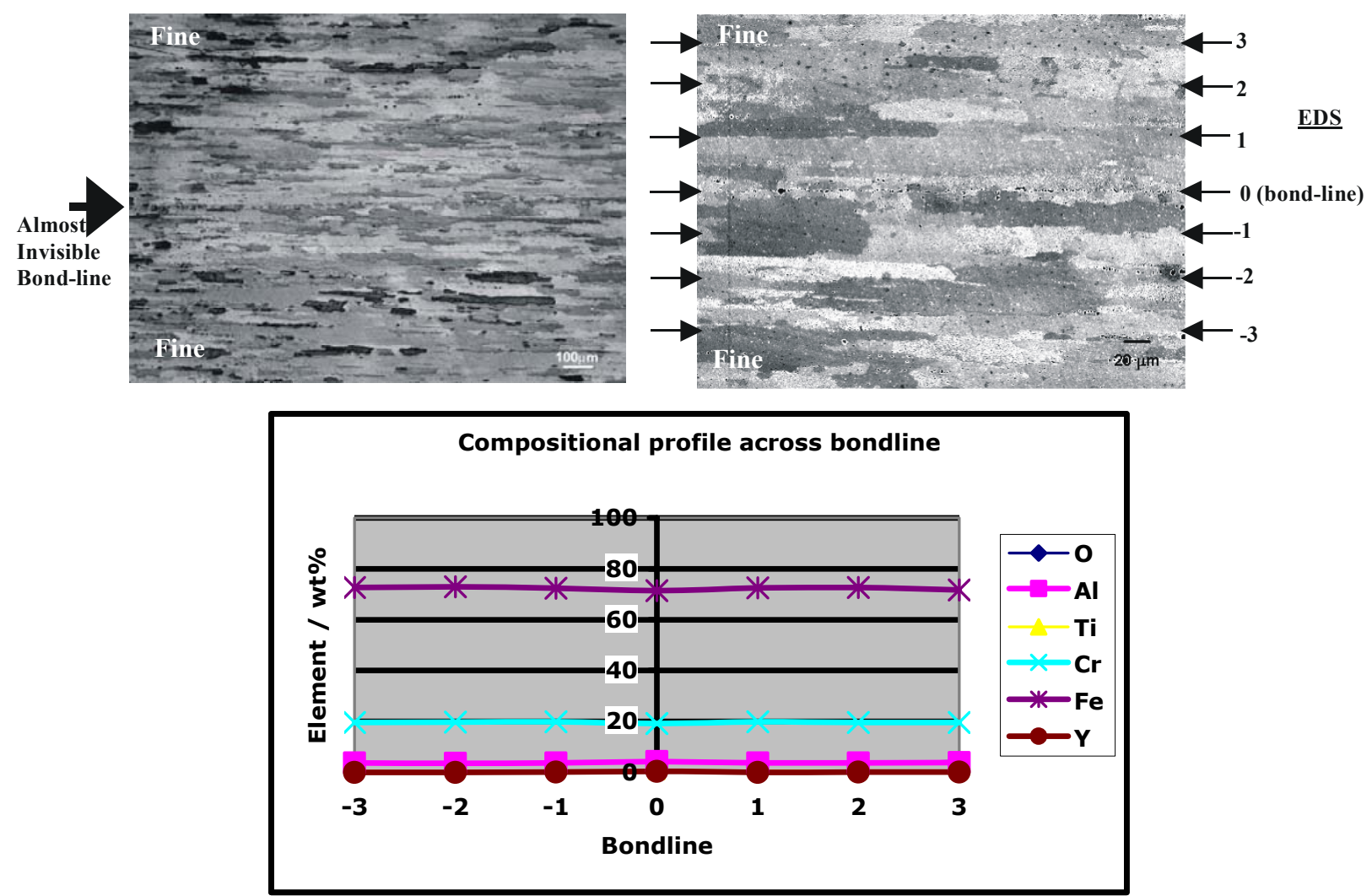

Figure 15. EDS compositional profile across the bondline. MA956 fine grain L-L orientation. Bond: 1 $\mu \mathrm{m}$ boron interlayer, $120 \mathrm{sec}$ at $1250^{\circ} \mathrm{C}$ and PBHT $1 \mathrm{hr}$ at $1300^{\circ} \mathrm{C}$. 

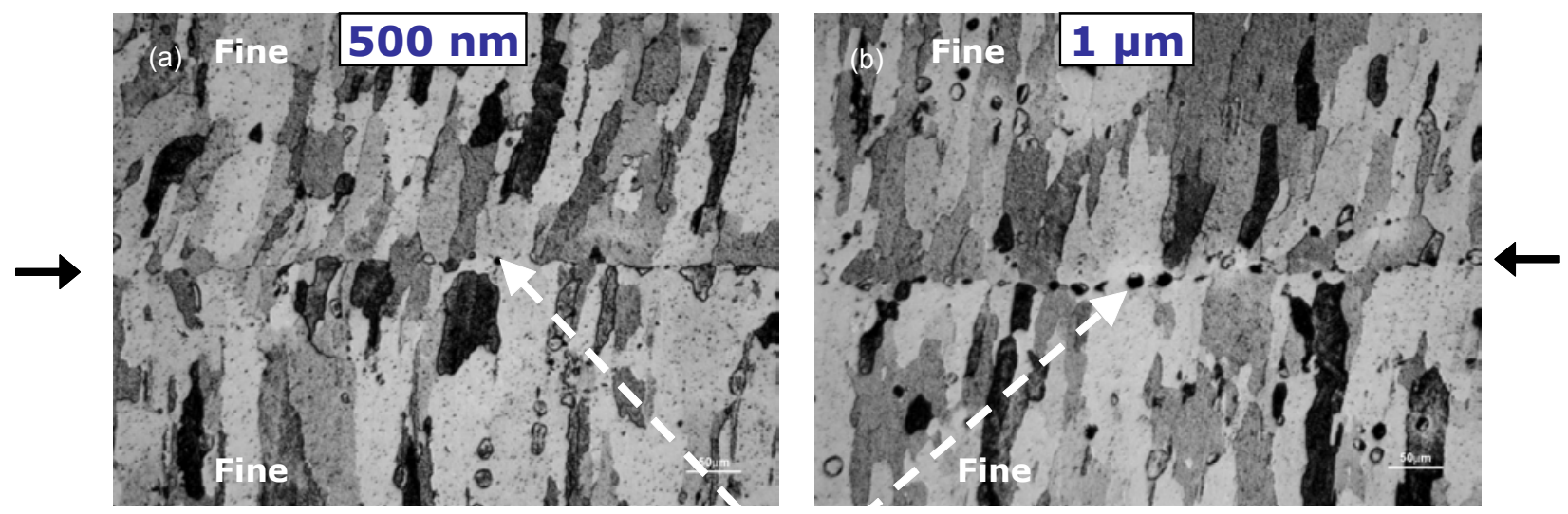

\section{Borides}

Figure 16. MA956 fine grain T-T orientation bond with (a) $0.5 \mu \mathrm{m}$ (b) $1 \mu \mathrm{m}$ boron interlayer. Bond cycle $1 \mathrm{hr}$ at $1250^{\circ} \mathrm{C}$, PBHT $1 \mathrm{hr}$ at $1300^{\circ} \mathrm{C}$.

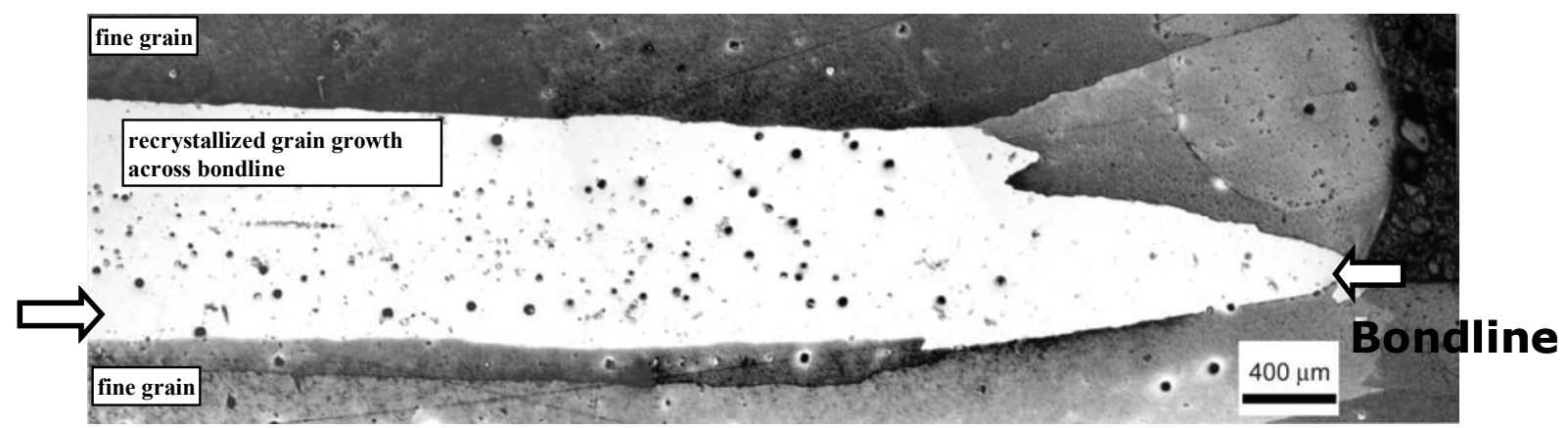

Figure 17. PM2000 fine grain bond L-L orientation with $0.25 \mu \mathrm{m}$ boron interlayer. Bond cycle $30 \mathrm{sec}$ at $1250^{\circ} \mathrm{C}$. PBHT $2 \mathrm{~h}$ at $1385^{\circ} \mathrm{C}$. 

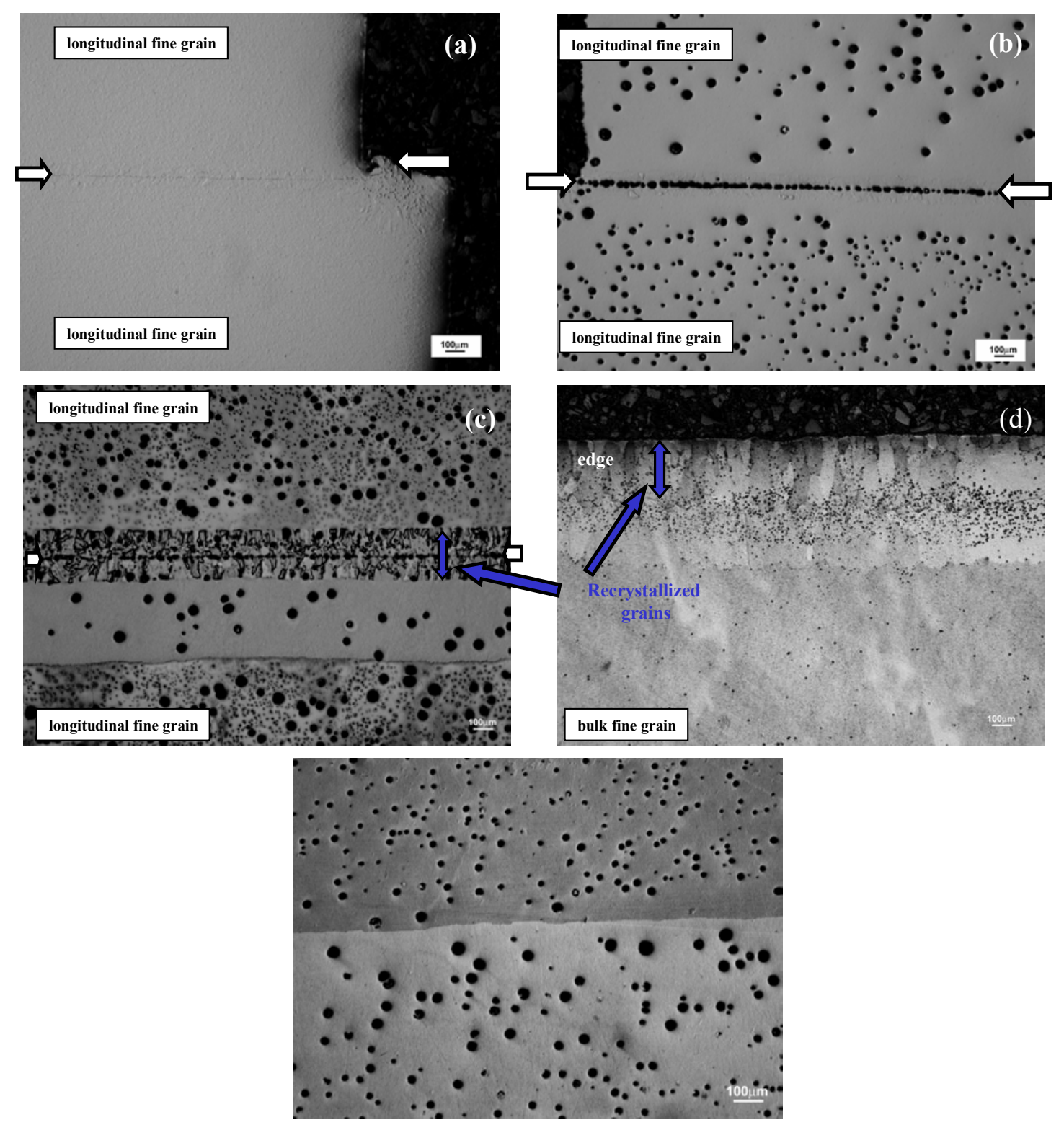

Figure 18: PM2000 fine grain material: (a) as-polished after bond cycle $300 \mathrm{sec}$ at $1250^{\circ} \mathrm{C}$; (b) aspolished after same bond cycle plus $2 \mathrm{hr}, 1385^{\circ} \mathrm{C}$ PBHT; (c) etched after $370 \mathrm{sec}$ at $1250^{\circ} \mathrm{C}$ bond cycle and $2 \mathrm{hr}, 1385^{\circ} \mathrm{C}$ PBHT; (d) and (e), recrystallized bulk substrate without bonding. Note the fine grain formation at the bondline in (c) and at the substrate edge in (d). Note pore formation in the bonds in the PBHT condition as compared to the as bonded condition, and the variation in pore formation in the unbonded bulk material (d) and (e).

\subsubsection{Diffusion Bonding}

Diffusion bonding was conducted using MA956 in the recrystallized and unrecrystallized conditions. Fine-grain - fine-grain, fine-grain - coarse-grain and coarse-grain - coarse-grain substrates were bonded at $1250^{\circ} \mathrm{C}$ for up to $600 \mathrm{sec}$, followed by a PBHT of $1 \mathrm{hr}$ at $1300^{\circ} \mathrm{C}$. Bonding occurred only when fine grain material was involved (Figures 19a and 19b). Large unbonded regions were observed in the coarse-grain - coarse-grain bonds (Figure 19c). Due to the high strength of the recrystallized ODS alloys, it is difficult to deform the coarse-grained substrates and achieve the necessary intimate contact 
between faying surfaces required for diffusion bonding. Fine grain sizes (less than $10 \mu \mathrm{m}$ ), however, can lead to high grain boundary diffusion rates contributing to void closure and hence result in a significant increase in the bonding rate [19-21]. Unrecrystallized ODS alloys possess huge amounts of stored energy [22], which might also contribute to the bonding of MA956 when joining unrecrystallized material.

Diffusion bonding of PM2000 in the fine grained condition was conducted at $1250^{\circ} \mathrm{C}$ for up to 600 $\mathrm{sec}$ in longitudinal-longitudinal and transverse-transverse bond orientations. Bonding occurred in both cases. Figure 20 shows a well-bonded sample in the longitudinal-longitudinal condition is shown in the as-bonded (as-polished) condition. The best results to date show 100\% bonded area using relatively low applied stresses of 1-5 MPa. Bonds conducted in the transverse-transverse orientation also exhibited good bonding. Void formation observed in the transverse-transverse orientation bonds decreased with increasing bond time, as shown in Figure 21. Recrystallization occurred in the substrates during PBHT, but pore formation also took place; pore formation in the bondline area can be observed in Figure 22.
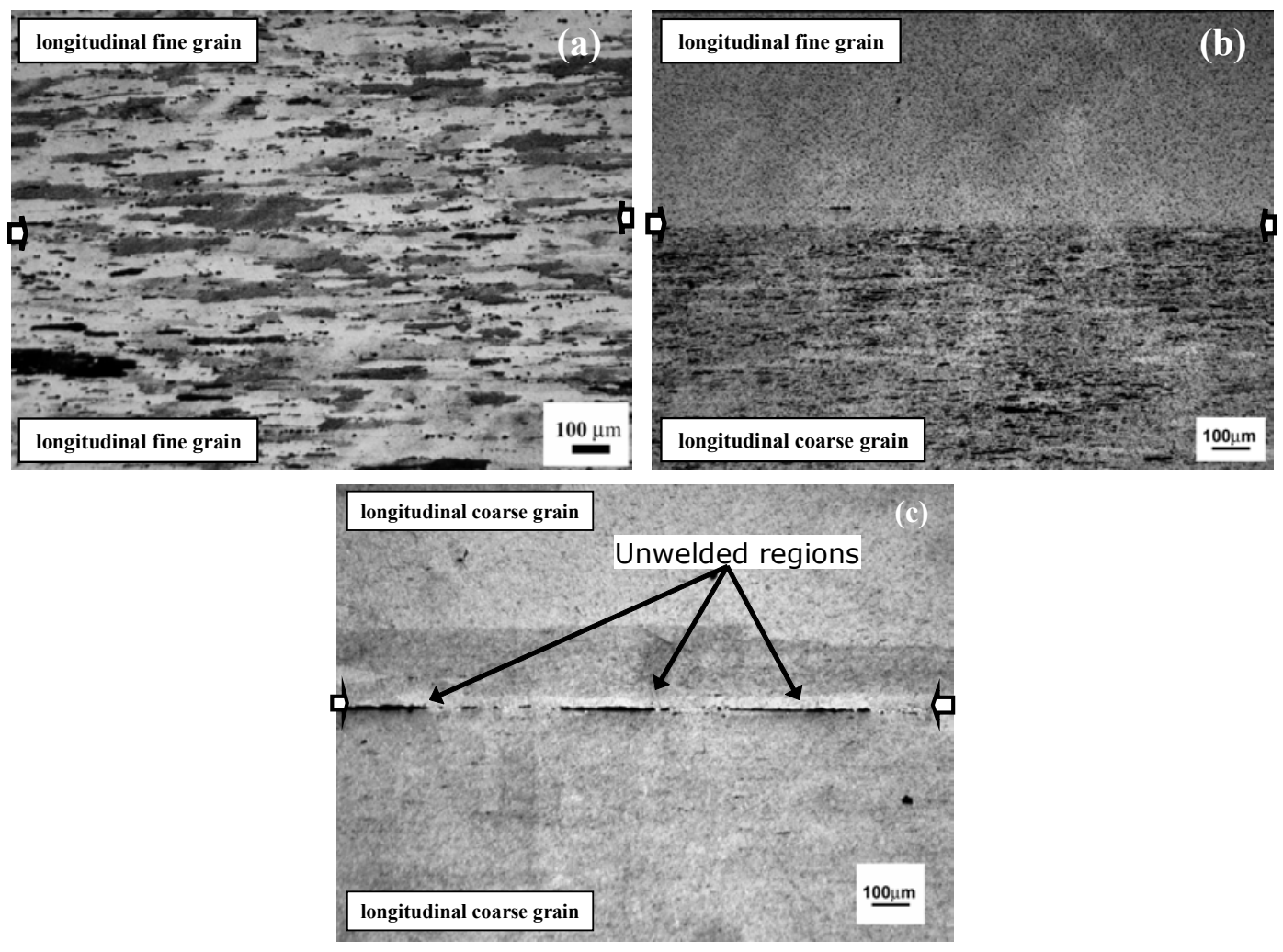

Figure 19. MA956 longitudinal-longitudinal orientation bonded at $1250^{\circ} \mathrm{C}$, PBHT $1 \mathrm{hr}$ at $1300^{\circ} \mathrm{C}$ : (a) fine grain to fine grain, $121 \mathrm{sec}$, (b) fine grain to coarse grain, $170 \mathrm{sec}$ and (c) coarse grain to coarse grain, $174 \mathrm{sec}$. 

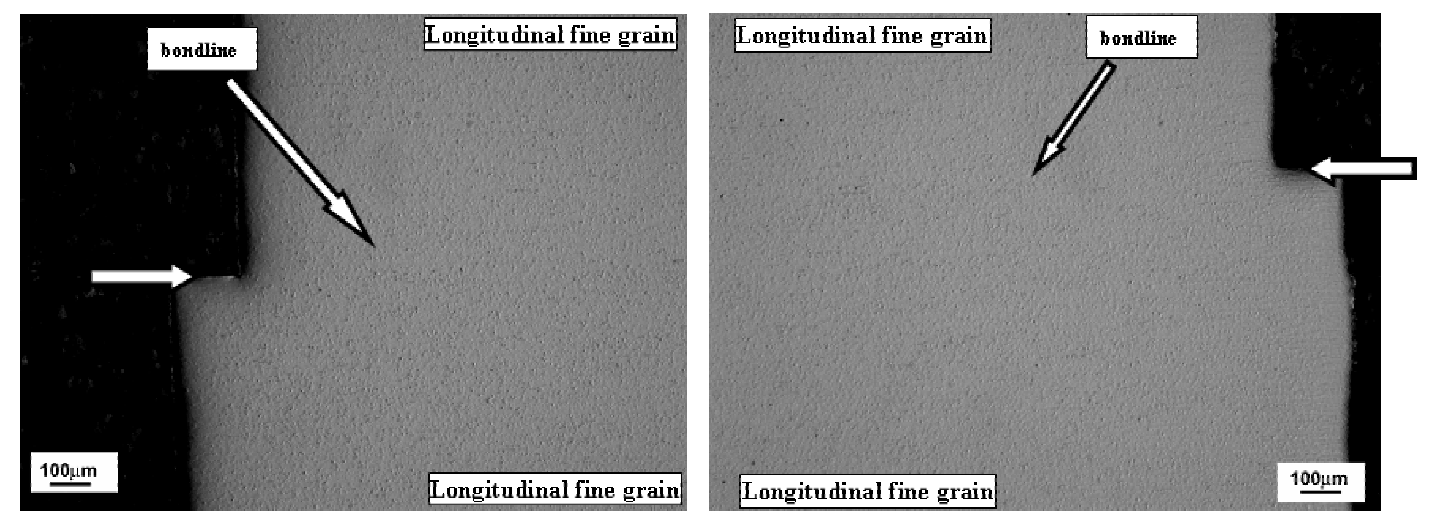

Figure 20. PM2000 fine grain longitudinal-longitudinal bond as-bonded (as-polished, unetched) $310 \mathrm{sec}$, $1250^{\circ} \mathrm{C}$. No voids were observed.
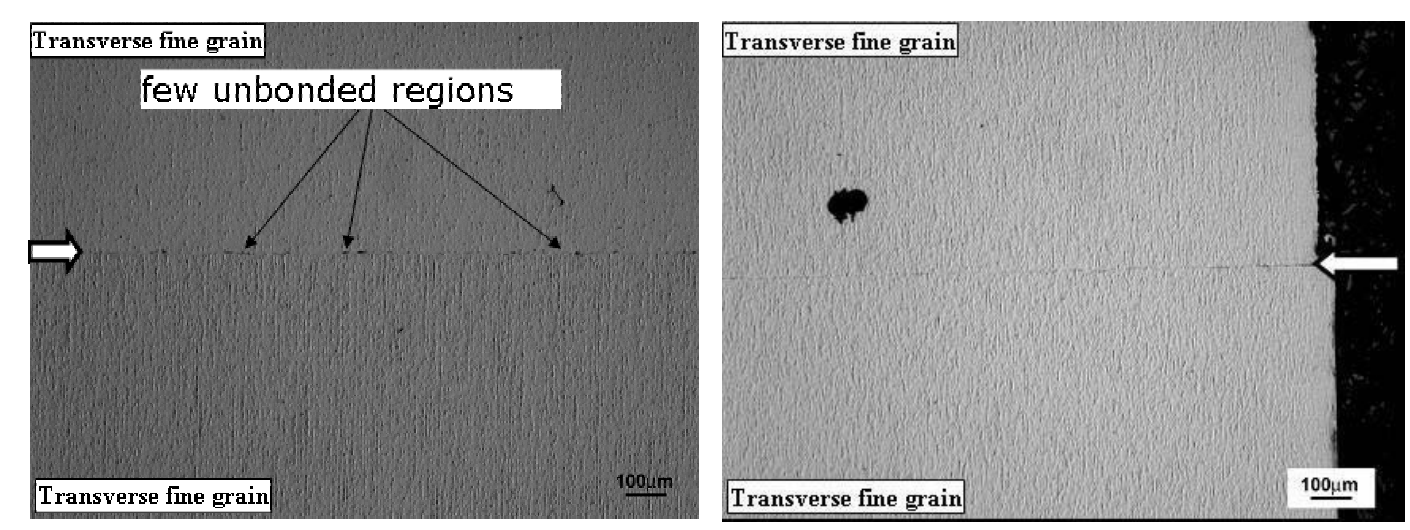

Figure 21. PM2000 fine grain transverse-transverse bond as-bonded (as-polished, unetched) $310 \mathrm{sec}$, $1250^{\circ} \mathrm{C}$. Note the decrease in voids with increase in the bond time.
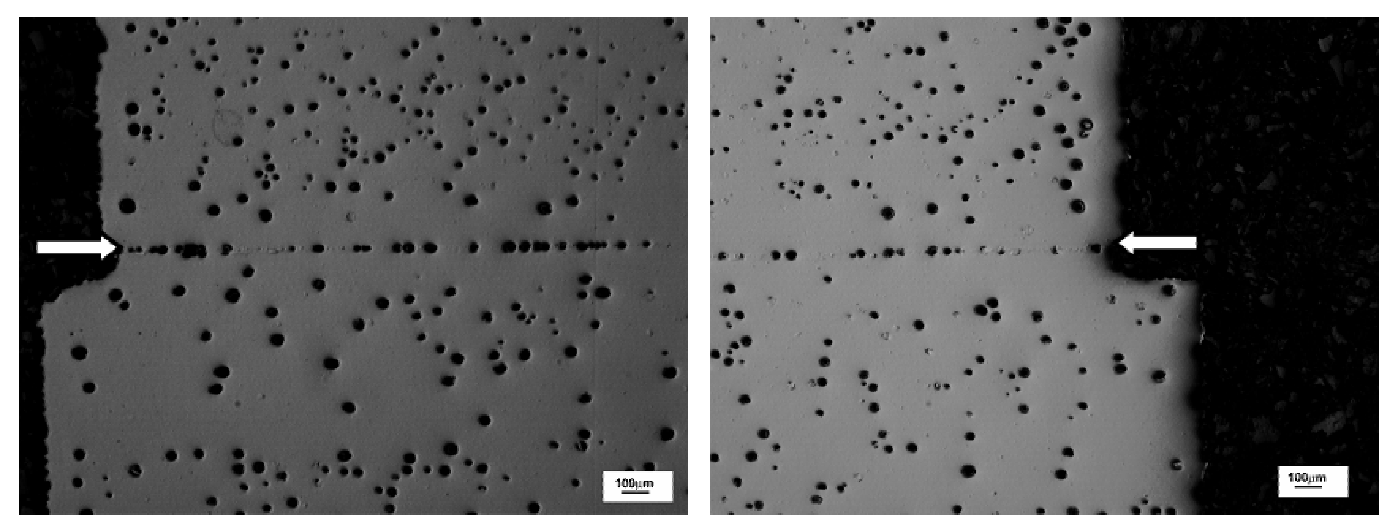

Figure 22. PM2000 fine grain longitudinal-longitudinal bond post bond heat treated (as-polished, unetched) $310 \mathrm{sec}, 1250^{\circ} \mathrm{C}$ and $2 \mathrm{~h}, 1385^{\circ} \mathrm{C}$. Note the porosity after PBHT in the same bond as in Figure 20 . 


\subsubsection{Room-Temperature Shear Testing}

Shear testing has been and will continued to be used as a quick and inexpensive tool for identifying poorly performing bond conditions. Tests have been conducted to date on PM2000 diffusion bonds, fabricated using unrecrystallized, fine-grained substrates in both longitudinal-longitudinal and transversetransverse orientations. Bonding was followed by PBHT of $2 \mathrm{hr}$ at $1385^{\circ} \mathrm{C}$. For comparison, shear tests were conducted on bulk material in both the fine-grained condition and after recrystallization annealing. The peak shear stress values of the tests in both orientations are shown in Figure 23. The peak shear stress of the recrystallized bulk material is lower than the as-received, unrecrystallized bulk material, a result expected due to the high grain boundary density in the fine-grained material. A variation in peak shear stress with orientation of the substrate was also observed; the transverse orientation showed higher peak shear stress than the longitudinal orientation. Shear strengths of bonds after PBHT in both orientations were on the order of $70 \%$ of the bulk recrystallized material. Although, the bonded area in the as-bonded condition can reach up to $100 \%$, a decrease in the bonded area due to pore formation during PBHT occurs, which may account for the decrease in strength. Shear tested specimens were examined in the SEM and fracture was observed to occur at the bondline (Figure 24). The fracture surfaces of the bonds and the bulk exhibit mostly planar shear fracture with some secondary cracking.

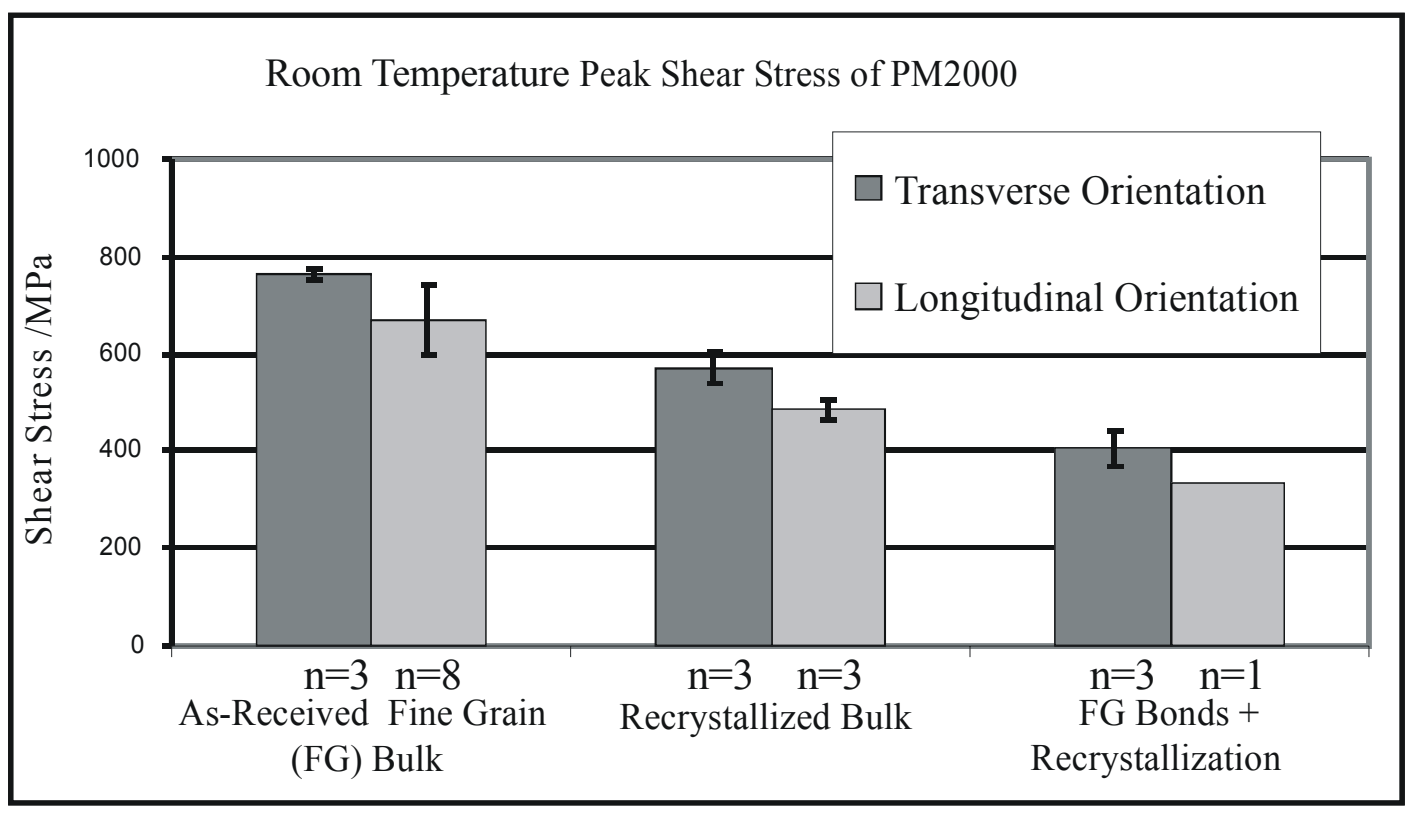

Figure 23. Room temperature shear tests of PM2000 in as-received fine-grained condition, recrystallized condition and bonded + recrystallized condition in both transverse and longitudinal orientations. The error bars represent standard deviation of the test results and $n$ represents the number of tests conducted. 

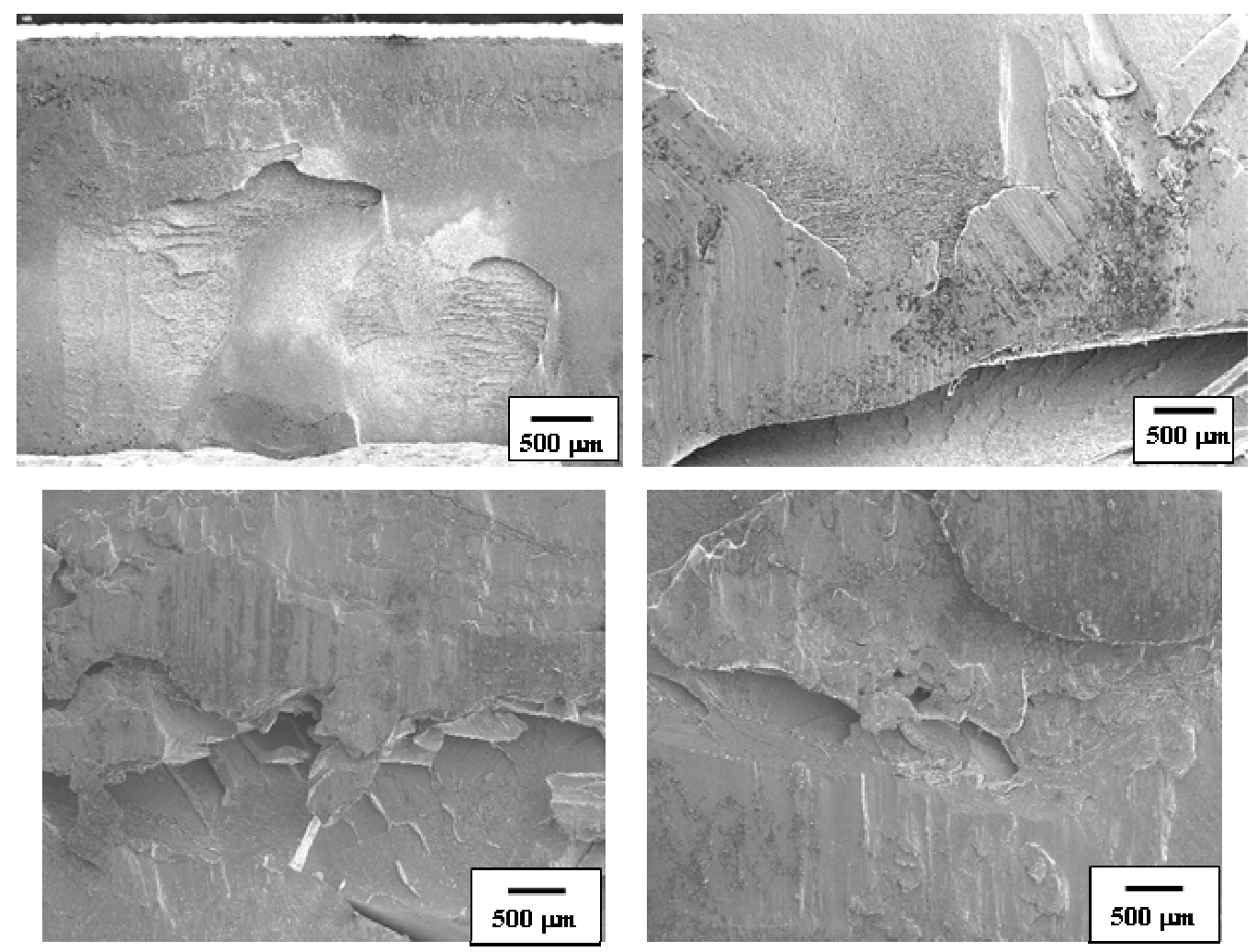

Figure 24. Fracture surfaces of PM2000 material: (a) bulk fine grain condition in transverse orientation; (b) bulk fine grain condition in longitudinal orientation; (c) and (d) are of opposite surfaces of a fine grain transverse-transverse bond $300 \mathrm{sec}$ at $1250^{\circ} \mathrm{C}$ and PBHT $2 \mathrm{hr}$ at $1385^{\circ} \mathrm{C}$. Mostly planar fracture occurred in the material. Some secondary cracking was also observed.

\subsubsection{Future Work}

In order to minimize porosity formation due to gas release during the recrystallization heat treatment of PM2000 a two-stage post-bond heat treatment will be investigated. The two-stage heat treatment involves pre-annealing at a lower temperature for a prolonged time in vacuum followed by the standard recrystallization heat treatment $\left(1385^{\circ} \mathrm{C}\right.$ for PM2000). Chen et al. [23] were able to reduce porosity using such dual-stage heat treatment, but it was not completely eliminated.

Bonding will be continued using PM2000 material by both TLP and diffusion techniques. Shear tests will be conducted in the as-bonded condition in order to see the effects of recrystallization on the mechanical properties of the bonds. Creep tests of bonds will also be performed, but it will be important to reduce the porosity in the material, before creep testing due to deteriorating effects of porosity on creep strength.

Isothermal heat treatments have been employed to date for recrystallization purposes. In general, the use of zone annealing, versus isothermal annealing, has little effect on ferritic ODS alloys. However, zone recrystallization annealing has been reported to produce epitaxial grain growth across the bond interfaces $[14,15]$ and is worth exploring. Induction heating will be used for moving zone annealing recrystallization. 


\section{General Comments and Conclusions}

Due to the strong dependence of creep strength on grain size and aspect ratio for ODS alloys [24], retaining the original grain structure in ODS alloy joints will be critical for higher-temperature applications, such as those envisioned in the GFR. In this respect the TLP and diffusion bonding techniques show the most promise, since consistent grain growth across the original bondline has been demonstrated when initially un-recrystallized parts are joined and then subjected to a recrystallization anneal as part of the post-bond heat treatment. Parts joined by the resistance forge welding process also have the potential for grain growth across the bondline, but the unavoidable disruption of oxide stringers during joining makes this unlikely.

Although the TLP bonding technique has shown promise in achieving the fundamental objective of producing bonded microstructure essentially identical to the parent material, additional engineering issues must still be addressed. One such issue is dimensional tolerance on joint parts. As pointed out in this report, the best joints produced use an extremely thin layer $(0.25 \mu \mathrm{m})$ of boron as an interlayer needed to create the bond. Nearly perfect alignment of faying surfaces is required for the boron to contact both surfaces equally and prevent formation of gaps. Such high tolerances will likely not be achievable in engineering practice. One possible solution to this issue would be the use of boron-coated ODS foils as interlayers. Bond and post-bond heat treatment of components may also be an issue; the temperatures are very high and the duration of exposure is in some cases relatively long.

The resistance pressure weld techniques demonstrated in this report and earlier [5] show excellent promise for joining components used at lower temperatures. The original development of this technique was for sodium-cooled fast reactor applications were temperatures do not exceed $700^{\circ} \mathrm{C}$. In this case creep strength of the ODS material is not as critical as radiation and phase stability. It would seem likely that the deformation and distortion of the alumina and yttria stringers which occurs in this technique would prevent grain growth across the bondline in subsequent recrystallization anneals, but the joint may have adequate strength for lower-temperature applications. In addition to the sodium-cooled fast reactor, this joining technique also holds promise for applications such as fuel cladding in the supercritical watercooled reactor, which operates in a similar intermediate-temperature regime.

This joining technique, in which heating is achieved by electrical resistance, is expected to produce stronger joints than the similar friction and friction-stir welding techniques which utilize frictional heating. In the latter cases extreme distortion of the microstructure occurs. Frictional techniques also require much higher forces than resistance pressure welding. Further research on the resistance pressure weld technique is recommended to produce quantitative creep strength data for welds made using an optimized torsional technique such as described in section 2.6. Joints made using initially coarse-grained (recrystallized) material will also be of interest, since this would eliminate the need for post-joining heat treatment.

\section{References}

1. C.Y. Kang, T.H. North, D.D. Perovic, Metall. Mater. Trans. A 27A (1996) 4019.

2. K. Shinozaki, C.Y. Kang, Y.C. Kim, M. Aritoshi, T.H. North, Y. Nakao, Weld. J. 76 (1997) S289. 
3. P.A. Molian, Y.M. Yang, P.C. Patnaik, J. Mater. Sci. 27 (1992) 2687.

4. T.J. Kelly, Weld. J. 61 (1982) S317.

5. J. Bottcher, S. Ukai, M. Inoue, Nucl. Technol. 138 (2002) 238.

6. T.J. Moore, T.K. Glasgow, Weld. J. 64 (1985) 219s.

7. T.I. Khan, E.R. Wallach, J. Mater. Sci. 30 (1995) 5151.

8. T.I. Khan, E.R. Wallach, Mater. Sci. Technol. 12 (1996) 603.

9. T.I. Khan, E.R. Wallach, J. Mater. Sci. 31 (1996) 2937.

10. D.S. Duvall, W.A. Owczarski, D.F. Paulonis, Weld. J. 53 (1974) 203.

11. W.F. Gale, D.A. Butts, Sci. Technol. Weld. Join. 9 (2004) 283.

12. G.E. Sheward, High Temperature Brazing in Controlled Atmospheres, Permagon Press, Oxford, 1985.

13. A.J. Markham. Ph.D. Thesis, University of Cambridge: Cambridge, UK (1988).

14. T.I. Khan. Ph.D. Thesis, University of Cambridge: Cambridge, UK (1992).

15. I.A. Bucklow, in: Advances in Joining Newer Structural Materials, Permagon Press, Elmsford, New York, 1990, p. 299.

16. G. Zhang, R.S. Chandel, H.P. Seow, H.H. Hng, Materials and Manufacturing Processes 18 (2003) 599.

17. M. Turker, J. Mater. Sci. 40 (2005) 1201.

18. Y.L. Chen, A.R. Jones, U. Miller, Metall. Mater. Trans. A 33A (2002) 2713.

19. B.S. Bokstein, V.S. Gostomelskii, V.A. Ivanov, A.L. Petelin, S.A. Petelin, Materials Letters 39 (1999) 77.

20. A. Hill, E.R. Wallach, Acta Metall. 37 (1989) 2425.

21. N. Orhan, M. Aksoyand, M. Eroglu, Mater. Sci. Eng. A271 (1999) 458.

22. H.K.D.H. Bhadeshia, Mater. Sci. Eng. A223 (1997) 64.

23. Y.L. Chen, A.R. Jones, Metall. Mater. Trans. A 32A (2001) 2077.

24. T.C. Totemeier and T.M. Lillo, Metall. Mater. Trans. A 36A (2005) 785. 